EConomía: Teoría y Práctica • Nueva Época, número 45, julio-diciembre 2016, pp. 97-136, http://www.izt.uam.mx/economiatyp/ojs

\title{
Cuantificación de los efectos de la disminución de remesas internacionales dirigidas a las regiones urbanas y rurales de México en 2002 mediante el uso de una matriz de contabilidad social*
}

\section{The Effects of the Decline of International Remittances in the Economy of Urban and Rural Regions of Mexico. A Social Accounting Matrix Approch 2002}

Lilian Albornoz Mendoza** y Rafael Ortiz Pech***

\section{RESUMEN}

En este artículo, se estiman los efectos multisectoriales de una reducción de las remesas internacionales que recibieron los hogares mexicanos en 2002. Para ello, se usa una matriz de contabilidad social correspondiente a 1996 en la que se desglosan las regiones rurales de México, actualizada a 2002 y balanceada con el método de entropía. Los resultados muestran que los efectos fueron mayores en la producción sectorial de agriculturaganadería, manufactura alimentaria, comercio, servicios y transporte. Además, el factor productivo más afectado globalmente es el trabajo urbano ligado a los sectores comercio $\mathrm{y}$ transporte, otros servicios y servicios profesionales. Con una baja de $10 \%$ en las remesas, el PIB se reduce 1\%. La mayor parte de la afectación total corresponde a la región urbana $(0.27 \%)$ y marginalmente a las rurales $(0.01 \%)$.

Palabras clave: remesas, regiones rurales, región urbana, matriz de contabilidad social, multiplicadores contables,

Clasificación JEL: C69, E16, E27.

\begin{abstract}
Multisectoral effects of a reduction in international remittances received by Mexican households are estimated. For this, a social accounting matrix of 1996 in which Mexico's rural regions are broken down is updated to 2002 by means of the entropy method. The results show that the effects were higher in the sectoral production of agriculture-livestock, food manufacturing, trade, services and transport. The most affected productive factor is urban work linked to the sectors of trade and transport, other services and professional services. Each 10\% less in remittances imply a decreased of $1 \%$ in GDP. Most of the effect corresponds to the urban region $(0.27 \%)$ and marginally to rural $(0.01 \%)$.
\end{abstract}

Keywords: remittances, rural regions, urban region, social accounting matrix, account multipliers.

JEL classification: C69, E16, E27.

* Fecha de recepción: 22/08/2013. Fecha de aprobación: 22/06/2016. Los autores agradecen la asistencia de Ariana Couoh Osorio y Hansell Sabido Ocampo, de la Facultad de Economía de la Universidad Autónoma de Yucatán.

** Universidad Autónoma de Yucatán. Correo electrónico: lilian.albornoz@correo.uady.mx.

*** Universidad Autónoma de Yucatán. Correo electrónico: rafael.ortiz@correo.uady.mx. 


\section{INTRODUCCIÓN}

Los efectos directos e indirectos de un impacto exógeno en la economía de un país, de un grupo de países, de una región o, incluso, de los hogares pueden estimarse a partir de modelos multisectoriales (Robinson, 1989; Sadoulet y De Janvry, 1995; Miller y Blair, 2009). La aplicación de este tipo de modelos requiere de una gran cantidad de datos, frecuentemente organizados a partir de matrices de contabilidad social (MCS) (Pyatt y Round, 1985; De Melo, 1988). En la presente investigación se elaboró una matriz de contabilidad social de México para el año 2002 (MCs 2002), con énfasis en sus regiones rurales, que actualiza la elaborada por Harris (2002) con datos de 1996 (MCs 1996) y que se balanceó por el método de entropía cruzada. La MCs 2002 se toma como base para la construcción de un modelo multisectorial de multiplicadores contables, con los que se estiman los posibles efectos de una reducción en las remesas que reciben del extranjero los hogares de México. ${ }^{1}$

El tema es relevante, entre otras razones, porque las remesas internacionales son una fuente importante de divisas en México (De la Fuente, 2010) ${ }^{2}$ y porque su flujo ha bajado a partir de la crisis internacional de 2008 (Ruiz y Vargas-Silva, 2012) y puede reducirse aún más por la disminución de las corrientes migratorias (Passel y Cohn, 2009), debida, en parte, a las políticas de contención y deportación masiva de inmigrantes indocumentados, sobre todo, por parte de Estados Unidos (EU), principal destino de los trabajadores mexicanos. En las condiciones actuales, de interdependencia económica global, los cambios en las circunstancias de los mercados internacionales afectan a las regiones urbanas y rurales en México a través de las remesas, como componente del ingreso de los hogares (Canales, 2008; Aragonés y Salgado, 2014).

La elaboración de la MCs 2002 se hizo en tres pasos. Primero, se actualizaron los totales por fila y columna de la MCs 1996 con base en información secundaria proveniente de fuentes oficiales. Segundo, se estimaron los valores de

\footnotetext{
${ }^{1}$ La MCS comprende las operaciones que los agentes de la economía doméstica realizan con el resto del mundo, por ejemplo, registra las importaciones internacionales de bienes y servicios y la recepción de remesas internacionales, transacciones que se agrupan en una sola cuenta denominada resto del mundo. Por lo anterior, el término "extranjero" comprende todas las operaciones que los agentes domésticos (por ejemplo, los hogares) realizan con personas o entidades residentes fuera del territorio económico o país, en cualquier parte del mundo.

${ }^{2}$ De la Fuente (2010) sostiene que las remesas superan los ingresos por concepto de turismo desde 1998. Además, han superado los montos de la inversión extranjera directa (IED) en la pasada década: en 2009, las remesas casi duplicaron los ingresos por concepto de IED.
} 
las celdas internas de la MCS 2002 a partir de la estructura de ingreso-gasto de la de 1996. Tercero, se balanceó la matriz resultante, porque, como es común en la elaboración de MCS, los totales de las filas y columnas no coinciden. En el caso de la MCs 2002, la falta de balance se debió a las inconsistencias en los datos de distintas fuentes de información y al uso de una matriz con una estructura antigua. Tradicionalmente, se ha utilizado el método llamado ajuste biproporcional (RAS) (Stone, 1962; Bacharach, 1970; Lahr y De Mesnard, 2004) para actualizar y balancear una MCS cuando se dispone de una matriz consistente de un periodo anterior. Con el método RAS se calculan los componentes internos a partir de los totales por fila y columna actualizados. Sin embargo, en años recientes, diversos investigadores han demostrado que el método de entropía ${ }^{3}$ es más eficiente para actualizar y balancear matrices, ya que permite incorporar información al interior de ellas (Robinson, Cattaneo y El-Said, 1998; 2011; Robinson y El-Said, 2000).

El presente trabajo tiene tres objetivos. El primero es exponer un método accesible y eficiente para balancear MCS a partir de la aplicación del método de entropía al proceso de actualización de la MCS 1996 a 2002 y ponerlo a disposición de los interesados en el análisis multisectorial. El segundo es contribuir al conocimiento de los posibles efectos económicos directos e indirectos de la reducción en el monto de las remesas internacionales que reciben los hogares de México. Por último, se busca determinar los mecanismos de transmisión de los efectos de una disminución de las remesas sobre los ingresos de los distintos tipos de trabajo rural (trabajo agrícola) y urbano (obreros, profesionales, empleados y personas ocupadas sin instrucción).

El artículo está dividido en cinco secciones. La primera expone la importancia de las remesas internacionales para la economía de los países y de los hogares; en la segunda, se muestran las fuentes de información utilizadas para la estimación de la MCS 2002, así como el procedimiento seguido para balancearla por entropía cruzada, y la tercera se aboca a los resultados de los multiplicadores contables estimados a partir de la MCs 2002. En la cuarta parte, se discuten los

\footnotetext{
${ }^{3}$ En específico, el RAS consiste en encontrar una nueva matriz de coeficientes basada en la original, generado una matriz de transacciones intersectoriales consistente con los nuevos totales de fila y columna. El balance de una matriz por este método tiene varios inconvenientes: primero, supone que la matriz original es consistente y está balanceada; segundo, que los nuevos totales de fila y columna son correctos, es decir, que no existen los llamados errores de medición; tercero, no permite incorporar información adicional (flujos al interior de la matriz) que pudiera mejorar la eficiencia de las estimaciones. Todos estos inconvenientes son superados por un nuevo método estadístico-econométrico, conocido como "de entropía".
} 
principales hallazgos sobre los efectos multiplicadores que tendría una disminución de $10 \%$ en las remesas que reciben los hogares urbanos y rurales de México, mientras que en la quinta se presenta el análisis estructural de trayectorias de la reducción del ingreso de los hogares rurales en dicho escenario. El artículo concluye con una serie de reflexiones sobre las resultados de la investigación.

\section{ReMESAS EN MÉXICO}

Los efectos de las remesas internacionales en la economía de los países se han medido en distintas vertientes, predominantemente, en el crecimiento económico y en la pobreza y la desigualdad del ingreso. En cada dimensión de análisis, la dirección de los impactos es un tema aún no resuelto. Los estudios que han encontrado una relación positiva y significativa de las remesas con el crecimiento económico de los países menos desarrollados sostienen que actúan como motor de la prosperidad debido a su influencia directa en el consumo, el ahorro y la inversión (Giuliano y Ruiz-Arranz, 2005; Fajnzylber y López, 2007; Catrinescu et al., 2009). Por el contrario, otros investigadores han encontrado relaciones negativas con el crecimiento económico (Chami, Fullenkamp y Jahjah., 2003; Barajas et al., 2009). Es decir, no se ha llegado a un consenso sobre si las remesas tienen un impacto positivo o negativo en el desarrollo sostenido aun cuando se han incrementado en todo el mundo durante las últimas décadas, un proceso interrumpido sólo en 2009, después de la crisis financiera global (World Bank, 2011). ${ }^{4}$ Por su parte, la literatura que consigna los efectos de las remesas internacionales sobre la pobreza y la desigualdad tiene dos vertientes: aquellos estudios que aportan evidencia de efectos positivos en la reducción de estos problemas (Taylor, 1992; Adelman, Taylor y Vogel, 1988; Esquivel y Huerta-Pineda, 2007; Imai et al., 2014) y los que han encontrado un efecto nulo o marginal, debido a que los hogares más pobres no siempre son los que las reciben (Wodon et al., 2004; Programa de las Naciones Unidas para el Desarrollo, 2007; De la Fuente, 2010), sino que suelen concentrarse en los menos pobres $^{5}$ (Lozano, 2005).

La mayoría de los estudios reseñados sólo ofrecen un panorama de los efectos parciales de primer nivel, sin profundizar en el análisis de las consecuen-

\footnotetext{
${ }^{4}$ En México, a partir de la crisis financiera que se inició a finales de 2008, los flujos de remesas internacionales no han vuelto a recuperar sus niveles previos (Banco de México, s.f.).

${ }^{5}$ Los sectores más desfavorecidos del país ni siquiera tienen la opción de migrar. El factor determinante central de la migración no es la pobreza sino las desigualdades (Programa de las Naciones Unidas para el Desarrollo, 2007).
} 
cias totales que experimentan las economías receptoras de las remesas internacionales. Convencionalmente, se enfocan en la medición de los resultados microeconómicos directos sobre los ingresos y los gastos de los hogares (Esquivel y Huerta-Pineda, 2007), sin cuantificar los efectos indirectos, inducidos y totales, sobre la economía estudiada (Adelman, Taylor y Vogel, 1988; Adelman y Taylor, 1990; Aguayo et al., 2009). Además, se presenta una dualidad entre las regiones rurales y urbanas, por lo que el estudio del impacto de las remesas debe distinguir los efectos diferenciados en cada una. El análisis de los efectos directos, indirectos, inducidos y totales por entorno rural y urbano es relevante porque aporta mayores elementos para dilucidar los efectos multiplicadores a una escala territorial más amplia. Hasta el momento no existe un estudio que aborde el problema desde dicha perspectiva, pues los realizados recientemente toman como referencia al país en su conjunto (Aguayo et al., 2009) o consideran sólo los efectos en las comunidades rurales (Adelman, Taylor y Vogel, 1988).

Además, este trabajo busca aportar información novedosa sobre la dirección y el peso relativo del impacto de las remesas internacionales en las regiones rurales y urbanas de México para que los tomadores de decisiones conozcan la ruta de transmisión de los efectos y su secuencia. Algunos estudios han abordado el fenómeno de la direccionalidad (Arroyo y Berumen, 2000), sin embargo, la metodología de la MCs permite, además, cuantificar el peso relativo de tales impactos (Adelman, Taylor y Vogel, 1988; Adelman y Taylor, 1990; Aguayo et al., 2009).

\section{ACtualización de La MCs 1996 de MÉXico al AÑo 2002}

La actualización de las MCs es un procedimiento que comúnmente comprende dos etapas: la estimación de la matriz macroeconómica agregada, que registra todas las transacciones que se realizan entre los principales sectores y agentes de la economía en el plano macroeconómico, y, seguidamente, la de la matriz microeconómica, que desagrega las subcuentas contenidas en la primera. La actualización de la MCS 1996 al año 2002 siguió el mismo procedimiento empleado por Harris (2002) para construir la matriz de que se parte, es decir, se procedió a elaborar una matriz agregada de diez cuentas (cuadro 1) con datos provenientes del Sistema de Cuentas Nacionales de México (SCNM) (INEGIa, s.f.) y del Banco de México (s.f.). ${ }^{6}$

${ }^{6}$ Barboza-Carrasco, Vázquez-Alvarado y Matus-Gardea (2009), construyeron una MCs 2004 con un procedimiento similar al empleado en este trabajo. 
102 ECONOMÍA: TEORÍA Y PRÁCTICA • Nueva Época, número 45, julio-diciembre 2016

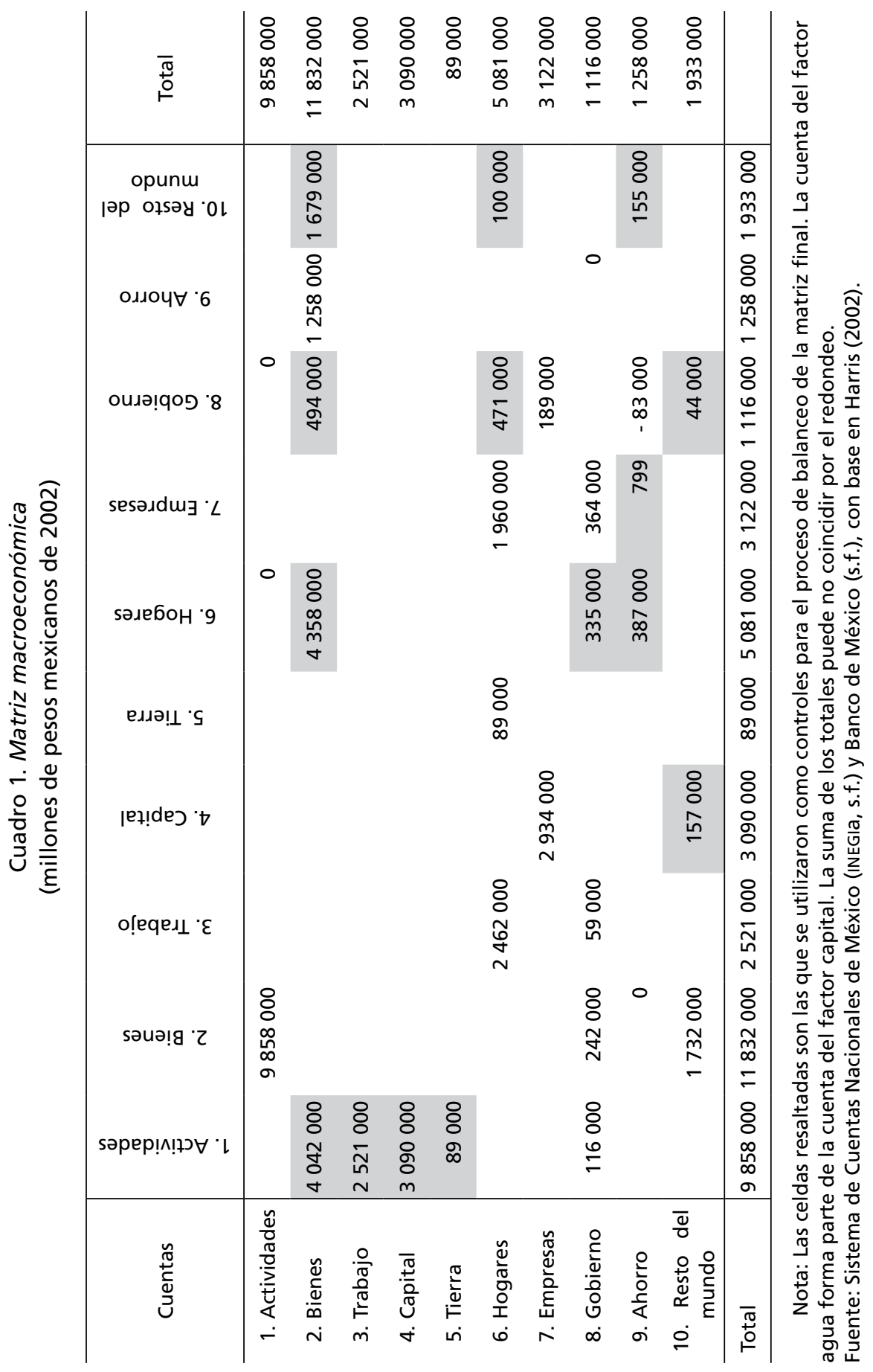




\section{Matriz macroeconómica}

Como su nombre lo indica, en esta matriz las cuentas se presentan de forma agregada y dan una idea de la estructura de la economía del país en el plano macroeconómico. La mayoría de la información proviene de una sola fuente: el SCNM (INEGIa, s.f.). A continuación, se describe el procedimiento por el que se obtuvueron los valores de las celdas y los totales de fila y columna por tipo de cuenta.

\section{a) Cuenta de actividades}

Esta cuenta representa las transacciones que realizan los productores de la economía doméstica con los distintos sectores e instituciones. En la columna, se registran el valor de los insumos intermedios que demandan las actividades en los mercados de bienes $^{7}(2,1)$; el valor agregado pagado a los distintos factores de la producción: trabajo $(3,1)$, capital físico $(4,1)$ y tierra $(5,1)$, y los impuestos al valor agregado que se pagan al gobierno $(8,1)$. El total de la columna $(11,1)$ corresponde al valor bruto de la producción a precios básicos. Por su parte, en la fila $(1,2)$, la cuenta consigna el valor bruto de la producción nacional, cuyo registro es idéntico al valor total de la columna de la misma cuenta.

La demanda de insumos intermedios en 2002 ascendió a un total de MXN 4.042 billones. En el SCNM (INEGIa, s.f.) se reporta el valor de tales insumos por un monto de MXN 4.212 billones, al cual le fue restado el valor de los servicios bancarios de ese mismo año, de MXN 85000 millones. En cuanto al valor agregado reportado en 2002, éste asciende a MXN 5.7 billones. Los salarios y remuneraciones que representan el pago al factor trabajo ascienden a MXN 2.521 billones. El SCNM (INEGIa, s.f.) no informa sobre las cantidades pagadas al capital físico y a la renta de la tierra, pero sí sobre el monto del excedente bruto de operación que comprende ambos. Lo pagado por las actividades del factor tierra se calculó usando el procedimiento empleado por Harris (2002) que consiste en emplear los datos de utilización de tierra y del valor bruto de la producción de los cultivos agrícolas del Servicio de Información Agroalimentaria y Pesquera (SIAP) de la Secretaría de Agricultura, Ganadería, Desarrollo Rural, Pesca y Alimentación (SAGARPA, s.f.). La suma pagada al capital físico se obtuvo restando el total del

\footnotetext{
${ }^{7}$ En esta sección, se indica entre paréntesis el número de fila y columna de la celda correspondiente a la matriz macroeconómica que se actualizó; por ejemplo, la celda $(2,1)$ corresponde a la intersección de la segunda fila con la primera columna (véase el cuadro 1).
} 
pago a los factores tierra y trabajo del valor agregado de la economía doméstica Por otra parte, el gobierno recibe de las actividades pagos por concepto de impuestos; se registra el impuesto al valor agregado menos los otros gravámenes a la producción. Durante 2002, los ingresos por este concepto ascendieron a MXN 116000 millones. Por último, la suma de los gastos (total de la columna) de la cuenta de actividades es el valor bruto de la producción (VBP) a precios básicos, de MXN 9.858 billones.

\section{b) Cuenta de bienes}

Esta cuenta representa el mercado de bienes que determina la oferta y la demanda agregadas. En la fila, se registra el valor de la demanda total por destino económico (intermedio y final) y la columna contiene la procedencia u origen geográfico de los productos que se consumen en el país (nacional o importado) que determina la oferta agregada. La demanda final en 2002 alcanzó un valor de MXN 7.789 billones de pesos. Dicha demanda está conformada por los bienes finales vendidos a los hogares $(2,6)$ por un valor de MXN 4.358 billones, mientras que al gobierno general se le vendieron bienes $(2,8)$ por una cantidad de MXN 494000 millones. La venta de bienes de capital y la variación de inventarios $(2,9)$ fue de MXN 1.258 billones; las exportaciones de bienes al resto del mundo $(2,10)$ alcanzaron el valor de MXN 1.679 billones. La demanda intermedia y la demanda final -el total de la fila $(2,11)$ - sumó MXN 11.832 billones. Por otra parte, el total de la columna es el valor de la oferta total compuesta por bienes nacionales e importados. La cuenta registra un monto por importación de bienes $(10,2)$ de MXN 1.732 billones y un pago por concepto de impuestos a las exportaciones e importaciones $(8,2)$ por MXN 242000 . La oferta total $(11,2)$ fue de MXN 11.832 billones de pesos en 2002. Esta cantidad excluye el valor de los bienes comprados directamente por los hogares al resto del mundo.

\section{c) Cuentas de factores}

En la matriz macroeconómica, los factores de la producción considerados tienen asignadas tres cuentas (con sus respectivas columnas y filas): trabajo, tierra y capital físico. El total de fila de la cuenta trabajo $(3,11)$ es el pago que realiza la cuenta de actividades por concepto de sueldos y salarios a los trabajadores de los distintos sectores económicos $(3,1)$. La columna de dicho factor distribuye el pago que recibe de las actividades (su valor agregado) entre los hogares (los 
dueños del factor o trabajadores) y entre el gobierno (contribuciones de los trabajadores para seguridad social). El factor trabajo distribuyó MXN 2.462 billones entre los hogares $(6,3)$ y pagó al gobierno (8,3) MXN 59000 millones en 2002.

El factor capital físico recibió ingresos de la cuenta actividades $(4,1)$ por MXN 3.090 billones y con ello pagó beneficios a las empresas $(7,4)$ por MXN 2.934 billones y realizó transferencias de capital al resto del mundo por concepto de rentas de propiedad $(10,4)$ por mXN 157000 millones. Por último, el factor tierra recibió ingresos de la cuenta actividades por el pago de sus servicios $(5,1)$ por un monto de MXN 89000 millones, el cual fue transferido en su totalidad a los hogares $(6,5)$.

\section{d) Cuentas institucionales}

Las cuentas institucionales corresponden a las de hogares, empresas y gobierno. La cuenta hogares recibe ingresos de los factores trabajo y tierra, así como de las otras instituciones (empresas y gobierno) y del resto del mundo. En 2002, los ingresos totales de los hogares $(6,11)$ del país ascendieron a MXN 5.081 billones, de los cuales una parte significativa proviene de los pagos realizado por el factor trabajo $(6,3)$ y por las empresas $(6,7)$. Adicionalmente, los hogares reciben transferencias del gobierno $(6,8)$, cuyo valor se obtuvo de las transferencias totales corrientes de los gastos presupuestales del gobierno federal (gasto programable) que divulga el Banco de México (s.f.). La cuenta resto del mundo también realiza transferencias corrientes a los hogares $(6,10)$ por concepto de remesas y otros rubros por MXN 100000 millones.

Gran parte de los gastos de los hogares se destinan a la compra de bienes de consumo final, que corresponde al valor de los gastos de consumo privado $(2,6)$, por MXN 4.358 billones de pesos. El pago de impuestos sobre el ingreso de los hogares al gobierno $(8,6)$ fue de mXN 335000 millones. Por último, la diferencia entre los ingresos totales y gastos totales es el ahorro de los hogares $(9,6)$, que alcanzó un valor de MXN 387000 millones de pesos.

Los ingresos de las empresas durante 2002 fueron de MXN 3.122 billones, los cuales provienen de los pagos que recibe de la cuenta de capital físico $(7,4)$, así como de transferencias del gobierno (subsidios) $(7,8)$. Los gastos de las empresas fueron de MXN 3.122 billones, que se distribuyeron a los hogares $(6,7)$ en forma de utilidades y al gobierno $(8,7)$ por concepto de impuestos. Los MXN 364000 millones asentados en la celda $(8,7)$ comprenden los impuestos indirectos y otros, como el ahora desaparecido Impuesto al Activo. El residuo de la 
columna de la cuenta son los ahorros $(9,7)$, los cuales podrán utilizarse en el periodo siguiente para financiar la inversión.

La fila de la cuenta del gobierno contiene los ingresos que recibe por el Impuesto al Valor Agregado $(8,1)$, impuestos a exportaciones e importaciones $(8,2)$, impuestos de seguridad social $(8,3)$, impuestos sobre el ingreso $(8,6)$, impuestos a los activos $(8,7)$ y otros. Los gastos corresponden a las adquisiciones de bienes $(2,8)$, las transferencias realizadas a hogares $(6,8)$ y a empresas $(7,8)$, el déficit de caja del gobierno federal (desahorro) $(9,8)$ y el pago de intereses al resto del mundo (10,8). El monto de los ingresos/gastos del gobierno en 2002 fue de MXN 1.116 billones.

\section{e) Otras cuentas}

En la cuenta ahorro se asienta el valor de la formación bruta de capital del país, el cual ascendió a 1.258 billones de pesos $(11,9)$. Las instituciones que financiaron la inversión son los hogares $(9,6)$, las empresas $(9,7)$ y el resto del mundo $(9,10)$; el gobierno incurrió en un desahorro $(9,8)$ que fue fondeado con préstamos en el mercado de dinero, de acuerdo con información tomada del Banco de México (s.f.). Por otra parte, la cuenta resto del mundo registra todas las transacciones externas del país por concepto de compra-venta de bienes, transferencias, inversión externa y préstamos financieros. En la columna de la cuenta se asientan los ingresos del país por la venta al extranjero de bienes (exportaciones FOB (free on board) $(2,10)$ y por las transferencias a los hogares provenientes del exterior $(6,10)$, como las remesas. En la columna también se asientan los montos de inversión extranjera directa (IED) y otro tipo de ingresos en forma de préstamos y depósitos $(9,10)$, cuya información se obtuvo del Banco de México (s.f.). Por su parte, la fila de esta cuenta registra los ingresos que esta entidad recibió de México por importaciones $(10,2)$, por rentas de propiedad pagadas $(10,4)$, así como por transferencias al exterior que realiza el gobierno federal por pago de intereses y amortizaciones $(10,8)$. El valor total de fila y de/columna de esta cuenta fue de 1.933 billones de pesos.

La MCS macroeconómica es relativamente sencilla de construir y balancear, ya que gran parte de la información de las celdas y los totales de fila y de columna provienen del SCNM (INEGia s.f.) y el Banco de México (s.f.). ${ }^{8}$ A partir

\footnotetext{
${ }^{8}$ Los valores de algunas celdas se estimaron como residuo con el fin de cuadrar la matriz macroeconómica. Por ejemplo, el ahorro de los hogares se obtuvo como la diferencia entre el total de los ingresos $(6,11)$, los gastos en bienes $(2,6)$ y los pagos de impuestos $(8,6)$.
} 
de la MCs 2002 y la MCS 1996, se fueron desagregando cada una de las cuentas en subcuentas hasta obtener 117 subcuentas (117 filas y 117 columnas) (anexo 1) para 2002, en la denominada matriz microeconómica. La desagregación consistió en obtener los valores totales de cada fila y columna para cada subcuenta con información de diversas fuentes oficiales (Centro de Estudios de las Finanzas Públicas, s.f.; INEGIa, s.f.; INEGib, s.f.; INEGIc, s.f.; Banco de México, s.f.; SAGARPA, s.f.). A diferencia de los totales de fila y columna, los valores de las celdas interiores de esta matriz se estimaron a partir de los coeficientes de propensiones medias al gasto de la MCs 1996, que, junto con los valores actualizados a 2002 de los totales de columna, permitió obtener una primera versión de la MCS 2002 microeconómica (matriz prototipo). ${ }^{9}$

Debido a que la información proveniente del SCNM (INEGIa, s.f) es consistente, los datos desagregados o microeconómicos se ajustaron de tal forma que en el agregado fueran iguales a los totales macroeconómicos ${ }^{10}$ de dicha fuente. Siguiendo a Harris (2002), las cuentas con mayor detalle en la MCs 2002 microeconómica corresponden a las de actividades y bienes (cada una comprende 21 sectores de la economía nacional); a las de factores productivos (nueve en total); y a las de hogares (seis, según nivel socioeconómico rural y urbano) (anexo 1).

Además, debido al enfoque del estudio y a la heterogeneidad geográfica del sector agrícola mexicano, las cuentas de actividades agrícolas, trabajo agrícola, tierra de temporal e irrigada, agua y hogares por nivel de ingreso, se distinguen por región rural: Norte, Centro, Suroeste, Sureste y la Río Bravo. ${ }^{11}$ Estas regiones están formadas por localidades con una población menor a 15000 habi-

\footnotetext{
${ }^{9}$ Esta primera versión de la matriz prototipo fue sometida posteriormente al balance por el método de entropía sujeta a restricciones en los flujos interiores de la matriz (entropía cruzada) (véase la sección II.3).

${ }^{10}$ Por ejemplo, los ingresos y gastos totales de los hogares que se obtuvieron de la Encuesta Nacional de Ingresos y Gastos de los Hogares (ENIGH) tuvieron que duplicarse para que coincidan con el total respectivo reportado por el SCNM (INEGIa, s.f.).

${ }^{11}$ Las diferencias más importantes entre las regiones rurales de México son las siguientes: la región Norte es árida, por lo que la producción agrícola requiere irrigación; lo obtenido se destina a la venta (comercial) y en parte se exporta. Es la que posee los cultivos con mayor valor agregado y cuyos hogares tienen ingresos más altos. En el otro extremo está la región Sureste, con elevados niveles de precipitación pluvial, con los hogares más pobres del país y cuya producción agrícola es de subsistencia. La Centro y la Suroeste se ubican, por sus características, entre los extremos descritos. La región Centro es una combinación de zonas templadas y áridas (que requieren irrigación) y sólo una porción de su agricultura es de subsistencia. La Suroeste es subhúmeda tropical, por lo que tiene una menor proporción de tierras irrigadas (Harris, 2002, p. 16). La Río Bravo presenta características similares a las regiones Centro y Norte.
} 
$\operatorname{tantes}^{12}$ (cuadro 2). Cada una tiene seis cuentas de actividades agrícolas y una sola cuenta global para ganadería, silvicultura y pesca (con excepción de la Río Bravo, para la cual se contó con datos para desagregar la actividad ganadera). En cuanto a los factores de producción, la MCS 2002 también distingue por región el trabajo agrícola, la tierra según tipo de recurso hídrico (de riego o de temporal) y el agua (anexo 1).

\section{Cuadro 2. Regiones rurales de México}

\begin{tabular}{lllll}
\hline \multicolumn{1}{c}{$\begin{array}{c}\text { Norte } \\
(1)\end{array}$} & \multicolumn{1}{c}{$\begin{array}{c}\text { Centro } \\
(2)\end{array}$} & \multicolumn{1}{c}{$\begin{array}{c}\text { Suroeste } \\
(3)\end{array}$} & \multicolumn{1}{c}{$\begin{array}{c}\text { Sureste } \\
(4)\end{array}$} & \multicolumn{1}{c}{$\begin{array}{c}\text { Río Bravo* } \\
(5)\end{array}$} \\
\hline Baja California & Durango** & Nayarit & Veracruz & Chihuahua \\
Baja California Sur & Zacatecas & Jalisco & Oaxaca & Coahuila \\
Sonora & Aguascalientes & Colima & Chiapas & Durango \\
Sinaloa & San Luis Potosín & Michoacán & Tabasco & Nuevo León \\
Chihuahua** & Guanajuato & Estado de México & Campeche & Tamaulipas \\
Coahuila** & Querétaro & Ciudad de México & Yucatán & \\
Nuevo León** & Hidalgo & Guerrero & Quintana Roo & \\
& Tlaxcala & Morelos & & \\
& Puebla & & & \\
& Tamaulipas** & & & \\
\hline
\end{tabular}

* Región formada con porciones de entidades que pertenecen a las regiones Norte o Centro.

** Entidades con una parte de su territorio asignado a la región Río Bravo.

Fuente: Harris, 2002.

La parte urbana de la MCs 2002 comprende todas las localidades con una población igual o mayor a 15000 habitantes de todo del país y está compuesta por actividades industriales y de servicios (catorce cuentas en total), incluyendo a profesionales, empleados, obreros y sin instrucción (anexo 2). Al igual que las

${ }^{12}$ La regionalización rural no corresponde a la determinada por el Instituto Nacional de Estadística y Geografía (INEGI) sino que fue construida de tal forma que los agentes e instituciones de una misma región compartieran características parecidas en cuanto a tecnología, formas de organización y niveles de bienestar. En este trabajo, la frontera entre rural y urbano se traza con base en la siguiente clasificación: las localidades rurales son las que cuentan con una población menor a 2500 habitantes; las semirrurales, las que tienen de 2500 a 14999 habitantes. Este umbral de 15000 habitantes se fijó con el fin de captar las diferencias en la estructura productiva agrícola entre las regiones rurales y semirrurales con respecto a las semiurbanas, de 15000 a 24999 habitantes, y las urbanas, con más de 25000 habitantes. 
regiones rurales, en las cuentas para el sector urbano se distinguen los hogares en tres niveles de ingreso.

Otras instituciones en esta matriz son las empresas, el gobierno y las asociaciones de usuarios de agua; estos últimos reciben el valor agregado del factor agua para riego, que canalizan a la cuenta de inversión. ${ }^{13}$ El resto de la MCS 2002 está compuesta por la cuenta del factor capital físico y las correspondientes al cierre macroeconómico (ahorro y resto del mundo).

A continuación se explica el procedimiento de desagregación para obtener la matriz microeconómica. ${ }^{14}$

\section{Matriz microeconómica}

\section{a) Cuentas de actividades}

Las actividades están desagregadas en 46 cuentas, que agrupan a 21 sectores de la economía nacional (anexo 1). Debido a que el estudio le otorga una mayor importancia al sector agrícola, existen seis cuentas por región rural asociadas a productos agrícolas; además, las cuentas de actividades comprenden otras seis cuentas del sector nacional de alimentos procesados, además de dos que corresponden al sector ganadería-silvicultura-pesca de la región Río Bravo y resto del país. Las cuentas agrícolas corresponden a la producción de maiz, frijol, trigo, otros granos, frutas y vegetales y otros cultivos; además, cada una está subdividida por región rural, de tal forma que, por ejemplo, hay cinco subcuentas asociadas a la cuenta maíz. El resto de actividades están agregadas para todo el país. Las seis cuentas del sector nacional de alimentos procesados corresponden a productos lácteos, frutas y vegetales preparadas, manufactura de trigo, manufactura de maiz, manufactura de azúcar y otros alimentos procesados. Además, los sectores de manufactura ligera, bienes de consumo, bienes intermedios, bienes de capital, servicios profesionales, otros servicios, construcción y comercio tienen asignada su cuenta respectiva.

\footnotetext{
${ }^{13}$ Para incorporar el agua de riego en la MCs 2002 se usaron los datos de los pagos de los agricultores a su correspondiente Asociación de Usuarios de Agua. El procedimiento anterior se explica por la ausencia de un cobro directo por el uso de tal recurso.

${ }^{14}$ Es común apoyarse en la matriz de insumo producto (MIP) para el proceso de desagregación de las cuentas de bienes y actividades, cuando está disponible (Núñez, 2014). Sin embargo, al no disponerse de una MIP 2002, se recurre a la información microeconómica de fuentes oficiales.
} 
El total de la columna de la cuenta de actividades corresponde al VBP de cada sector. La información sobre los cultivos agrícolas se obtuvo del SIAP (SAGARPA, s.f.). El valor bruto de la producción (tierra de riego y de temporal) reportada por dicha fuente es a precios de productor $^{15} \mathrm{y}$ se clasificó por región agrícola. En el caso de los cultivos cíclicos, el vBP corresponde al año agrícola de 18 meses, a diferencia de los cultivos perennes, cuyo año agrícola corresponde al normal de 12 meses. La estructura de la matriz implica que la producción agrícola sólo se tiene lugar en localidades con menos de 15000 habitantes.

El vBP y los costos de la ganadería para la región Río Bravo se estimaron a partir del Censo Agrícola y Ganadero 1991 (INEGId, s.f.) e información del SIAP (SAGARPA, s.f.) para el año 2002. El censo no incluye valores monetarios, pero contiene el número de unidades productivas y la cantidad de insumos utilizados. Como es una base de datos municipal, se logró información de los 141 municipios de la región Río Bravo, con la cual se calculó la proporción de insumos usados respecto al total de ella, en unidades. Finalmente, esta proporción se aplicó al VBP de dicha región por cada tipo de insumos de la MCs. La matriz original de Harris sólo incorpora una cuenta nacional de ganadería-silvicultura-pesca. El total para 2002 de la columna de dicha cuenta se obtuvo del SCNM (INEGIa, s.f.), que publica el dato a precios básicos, del cual se sustrajo el valor correspondiente a la cuenta de ganadería de la región Río Bravo. Por otra parte, las cuentas correspondientes a los sectores secundario y terciario fueron estimadas también con información de la misma fuente a nivel de rama de actividad.

\section{b) Cuentas de bienes}

Así como las cuentas de actividades corresponden a los productos vendidos en los mercados nacionales e internacionales, las de bienes corresponden a los 21 sectores nacionales descritos anteriormente. El total por columna de cada bien o sector económico es la suma de tres componentes: el VBP, las importaciones CIF (cost insurance and freight) y los derechos arancelarios. El valor de las importaciones se tomó de "Anuario Estadístico del Comercio Exterior de los Estados Unidos Mexicanos 2003” (INEGIc, s.f.), el cual publica información desagregada por fracción arancelaria y país de procedencia. Las importaciones incluyen el valor de los bienes con maquila y sin maquila y el monto de los servicios no fac-

${ }^{15}$ El VBP a precios de productor se ajustó al VBP a precios básicos del agregado de la cuenta actividades de la matriz macroeconómica con el método de balance por entropía. 
toriales (a precios de CIF). Los impuestos a las importaciones y exportaciones provienen de información del Banco de México (s.f.). Sólo para el sector construcción, el valor total de la cuenta fue tomado directamente del valor de la oferta total por actividad económica a precios de mercado del SCNM (INEGIa, s.f.).

\section{c) Cuentas de factores}

La literatura microeconómica distingue tres factores de producción: tierra, trabajo y capital. En este trabajo se incorpora el agua superficial, utilizada en la producción agrícola. Por otra parte, el factor trabajo comprende nueve cuentas: cinco corresponden a trabajadores agrícolas según región rural y las otras cuatro comprenden a trabajadores urbanos: profesionistas, obreros, empleados y $\sin$ instrucción. El total de la columna de las cuentas de trabajo es igual a la suma de los ingresos por tipo de trabajador y los impuestos por seguridad social, información que se tomó de la base de datos de la Encuesta Nacional de Ingresos y Gastos de los Hogares (ENIGH) del Instituto Nacional de Estadística y Geografía (INEGib, s.f.), la cual contiene el número de perceptores del hogar ocupados y su ingreso corriente monetario por ocupación en el empleo principal (secundario) por región.

En el factor tierra se separa la tierra de riego de la tierra de temporal. A cada tipo se le asignó una cuenta por región rural, por lo que existen diez cuentas asociadas a este factor. Los rendimientos, o renta de la tierra, se calcularon con datos del vBP y el uso de suelo por tipo de cultivo publicados por la SAGARPA (s.f.). Se siguió la metodología sugerida por Harris (2002), la cual consiste en multiplicar la superficie cultivada de cada grupo de cultivo de la MCs por la razón rendimiento temporal entre rendimiento riego y el precio rural promedio. El factor tierra se utiliza en la producción agrícola y, por lo tanto, es un factor de producción en el ámbito rural y no en el urbano.

El factor agua para riego comprende cinco cuentas, una por región rural. El valor total por fila y columna se calculó con datos sobre costos de operación y mantenimiento de los distritos de riego por municipio, según información de la Comisión Nacional del Agua (Conagua, s.f.). Tales costos son cubiertos por las asociaciones de usuarios de agua de los distritos de riego a partir de las cuotas que reciben de los agricultores con irrigación. Los desembolsos incluyen los pagos realizados para la operación y mantenimiento de la infraestructura de riego, la administración, la conservación, la distribución y el pago a canaleros y jornaleros; esto es, incluye todos los pagos realizados por el servicio de agua en los 
distritos de riego. Es decir que el usuario no paga por el agua, sino por el servicio, por lo que es más riguroso hablar de cuota y no de precio del agua. Los totales del pago por uso del agua por región rural se distribuyeron al interior de la MCS usando los mismos factores técnicos de producción contenidos en la cuenta tierra de riego de la MCS 1996. Por último, el total de la columna/fila de la cuenta de capital físico corresponde a la obtenida en la matriz macroeconómica. En total, son 25 cuentas de factores productivos agrupadas en nueve grandes categorías (anexo 1).

\section{d) Cuentas de los hogares}

Los hogares se clasificaron de acuerdo a su nivel de ingreso (pobres, clase media y ricos) y ubicación geográfica (seis regiones: cinco rurales y una macrourbana). Los hogares pobres son aquéllos ubicados en los primeros cuatro deciles de ingreso; los de clase media, en los siguientes cuatro deciles, y los hogares ricos, en los dos últimos deciles. En total, la MCs tiene 18 cuentas de hogares que se agrupan en seis grandes categorías (anexo 1). Los ingresos y gastos de los hogares se obtuvieron de la base de datos de la ENIGH 2002 (INEGIb, s.f.).

\section{e) Otras cuentas}

El total de las cuentas de gobierno, empresas, ahorro y resto del mundo tomó los valores estimados en la matriz macroeconómica. Otras cuentas son la de impuestos indirectos y la de impuestos directos, cuyos valores totales se descontaron de la cuenta gobierno. Por último, se agregó una cuenta adicional denominada rentr, que acumula los pagos de las cuentas de agua y los distribuye a la cuenta de ahorro (inversión).

\section{BalanCe de la mCs 2002 Para MéXico}

A partir de los totales de columna de 2002 y con base en la matriz $A$ de propensiones medias ${ }^{16}$ de 1996 , se estimó una primera versión de la matriz de flujos

\footnotetext{
${ }^{16}$ Un elemento $a_{i j}$ de la matriz de propensiones medias $A$ es un cociente dado por el valor de la celda $t_{i j}$ de cada columna $y_{j}$ de la matriz de transacciones (flujos) $T$ por su respectivo total de columna . En términos algebraicos $a_{i j}=\frac{t_{i j}}{y_{j}}$. El subíndice $i$ es el número de fila y el subíndice $j$ indica el número de columna de la matriz correspondiente.
} 
para 2002 (matriz prototipo). Sin embargo, es muy probable que entre 1996 y 2002 la economía haya experimentado cambios en su estructura, de tal forma que la MCS obtenida de esta forma no reflejaría la estructura de la economía en este último año y no estaría balanceada. Los dos inconvenientes fueron resueltos usando el método de entropía cruzada.

Dicho método permite la actualización de los flujos al interior de la MCS prototipo a partir de los nuevos totales de fila y de columna. Reconfigura la información conforme a los cambios generados en la economía en el periodo transcurrido debidos a mejoras tecnológicas o en las relaciones de insumo-producto, así como en la estructura de ingreso y gasto de los agentes económicos. Además, permite el balance de la MCS al ofrecer una vía de reconciliación de las inconsistencias de los datos contenidos en los totales de filas y columnas actualizadas.

Hay dos versiones del método de entropía: la de máxima entropía y la de entropía cruzada. La primera realiza la actualización y el balance de matrices sin incluir restricciones en los flujos internos de las cuentas. Por su parte, la de entropía cruzada permite mejorar las estimaciones de la anterior al controlar dichos flujos internos, ${ }^{17}$ ajustando los totales contenidos en determinadas submatrices de la MCS prototipo con los valores actualizados de agregados macroeconómicos (PIB, VAB, importaciones y exportaciones).

El problema matemático del método de entropía cruzada consiste en estimar los elementos de la matriz $A$ de propensiones medias al gasto de dimensión $n \times n$ y se plantea de la forma siguiente:

$$
\operatorname{Min}\left[\sum_{i} \sum_{j} a_{i j} l n \frac{a_{i j}}{a_{i j}^{0}}\right],
$$

sujeto a:

$$
\begin{gathered}
\sum_{j} a_{i j} y_{j}=y_{i} \\
\sum_{j} a_{i j}=1
\end{gathered}
$$

\footnotetext{
${ }^{17}$ A diferencia del método RAs, el de entropía cruzada mejora las estimaciones al tener la posibilidad de controlar los flujos internos y los totales de fila y columna de la MCs de tal manera que puedan ser consistentes con los agregados macroeconómicos. El método de entropía permite el uso de una mayor cantidad de información, no únicamente de flujos particulares exógenos, sino también de agregados de datos y acotaciones de los mismos, lo cual lo convierte en un método poderoso (Oliva, 2012). Actualmente, se ha desarrollado unna combinación del método de entropía con técnicas de simulación de Monte Carlo en estimaciones de mCS (Scandizzo y Ferrarese, 2015).
} 


$$
\begin{gathered}
a_{i j} \geq 0 \\
\sum_{i} \sum_{j} g_{i j}{ }^{(\mathrm{k})} t_{i j}=\gamma^{(\mathrm{k})},
\end{gathered}
$$

donde $a_{i j}^{0}$ es un elemento de la MCs 1996 de propensiones medias al gasto $A^{0}$. La ecuación (1) representa la restricción de que los totales de fila y de columna de la matriz estimada coincidan. La ecuación (2) representa la restricción de que la suma de los elementos de cada una de las columnas de la matriz $A$ de propensiones estimada sea igual a 1. La ecuación (3) indica que los elementos de la matriz estimada deben ser iguales o mayores a cero (no negatividad) y la ecuación (4) son los controles de los flujos internos, donde la matriz $G$, de dimensión $n \times n$, comprende 1 en las celdas que se tratan de controlar y 0 en todas las demás celdas $y$ es el macrototal. Pueden existir $k$ restricciones, a conveniencia del investigador.

El primer paso para balancear la MCs 2002 fue aplicar el método de máxima entropía de acuerdo al código desarrollado por Robinson, Cattaneo y ElSaid (2001) en el paquete computacional General Algebraic Modeling System (GAMS). En una segunda etapa, se incorporaron restricciones lineales al problema de balanceo que sirvieron para controlar los totales de filas, columnas y las diferentes submatrices que conforman la matriz de flujos. Las restricciones corresponden a los valores contenidos en la matriz agregada de diez cuentas (cuadro 1), de tal forma que el planteamiento de la estimación respetara los valores fijados por el SCNM (INEGIa, s.f.) para 2002. Las restricciones lineales incorporadas son: valor agregado, demanda intermedia, exportaciones, pagos al factor tierra, consumo privado, consumo del gobierno, transferencias de capital al resto del mundo, ahorro de hogares, ahorro de empresas, transferencias del gobierno a hogares, pagos del gobierno al resto del mundo, transferencias del resto del mundo a los hogares, transferencias de capital del resto del mundo al país e impuestos de seguridad social, impuestos a bienes y actividades.

\section{ESTIMACIÓN DE MULTIPLICADORES CONTABLES}

El análisis de multiplicadores contables es una primera aproximación a los efectos directos e indirectos de un cambio unitario en la demanda exógena de un sector o de la economía en su conjunto. La amplitud de los efectos totales del cambio en la demanda exógena depende, fundamentalmente, de los supuestos que subyacen al modelo de multiplicadores: capacidad ociosa de las empresas; industrias de costos constantes y, por lo tanto, precios de factores; precios de 
bienes y servicios constantes; así como propensiones marginales y medias al gasto constante por parte de los hogares y otras instituciones (elasticidad ingreso-gasto unitario). Estos supuestos condicionan de manera importante los resultados que arroja el modelo.

El modelo de multiplicadores contables está dado matricialmente por la ecuación $y=(I-A)^{-1} x$, donde $(I-A)^{-1}$ es la matriz de multiplicadores contables, $x$ representa la inyección de las cuentas exógenas y y los ingresos de las cuentas endógenas. Las cuentas exógenas están dadas por: gobierno, impuestos directos, impuestos indirectos, ahorro y resto del mundo. La matriz de multiplicadores, por lo tanto, tiene una dimensión de 112 filas por 112 columnas.

Cada elemento contenido en las celdas de la matriz de multiplicadores indica el cambio en los ingresos de la cuenta $i$ ante el cambio en una unidad monetaria en la demanda exógena de $j$. Hay dos tipos de multiplicadores, según se trate del total de columna o el total de fila de la correspondiente matriz (Barceinas, Crowe y Yunez-Naude, 1997):

a) Total de columna. También se denomina efecto sector-economía. Se refiere el modo en que un cambio de una unidad monetaria en la demanda exógena de una cuenta específica afecta al resto de la economía.

b) Total de fila. También se denomina efecto economía-sector. Indica de qué manera un cambio de una unidad monetaria en la demanda exógena de todas las cuentas afecta a una cuenta en particular.

En el cuadro 3 y la gráfica 1 se presentan los resultados de las estimaciones. ${ }^{18}$ Como se observa, hay importantes diferencias en los efectos sector-economía de las distintas cuentas endógenas (actividades, bienes, factores productivos, hogares y empresas) con valores máximos de 15.62 y mínimos de 1 . Sin embargo, en la gran mayoría (80 cuentas de 112) los efectos multiplicadores sectoreconomía tienen un valor de entre MXN 9.16 y MXN 12.34 por unidad monetaria de estímulo.

Siguiendo con los multiplicadores sector-economía, las cuentas cuya contracción tienen más impacto en la economía son las asociadas a la cuenta actividades, en especial trigo en las regiones rurales 1 (Norte), 2 (Centro) y 3 (Suroeste) con multiplicadores en el rango de MXN 14.12 a MXN 15.62; y otros granos (sorgo) en las regiones 1, 2, 3 y 5 (Río Bravo) con multiplicadores en el

\footnotetext{
${ }^{18}$ Los multiplicadores en la diagonal principal incluyen el peso de estímulo inicial.
} 
116 ECONOMÍA: TEORÍA Y PRÁCTICA • Nueva Época, número 45, julio-diciembre 2016

\section{Cuadro 3. Multiplicadores contables \\ (pesos mexicanos)}

\begin{tabular}{|c|c|c|c|c|c|c|c|c|}
\hline Cuenta & $\begin{array}{c}\begin{array}{c}\text { Economía- } \\
\text { sector }\end{array} \\
\end{array}$ & $\begin{array}{c}\text { Sector- } \\
\text { economía }\end{array}$ & Cuenta & $\begin{array}{c}\begin{array}{c}\text { Economía- } \\
\text { sector }\end{array} \\
\end{array}$ & $\begin{array}{c}\text { Sector- } \\
\text { economía }\end{array}$ & Cuenta & $\begin{array}{c}\begin{array}{c}\text { Economía- } \\
\text { sector }\end{array} \\
\end{array}$ & $\begin{array}{c}\text { Sector- } \\
\text { economía }\end{array}$ \\
\hline Amaíz1 & 1.45 & 9.70 & Aotrosalim & 17.32 & 10.89 & Ftrabobr & 16.31 & 11.00 \\
\hline Atrigo1 & 2.27 & 15.62 & Amanuflig & 12.25 & 9.99 & Ftrabnocap & 13.46 & 11.19 \\
\hline Afrijol1 & 1.26 & 9.84 & Abieninter & 10.60 & 9.64 & Ftierratemp1 & 2.82 & 8.43 \\
\hline Aotrosgranos 1 & 1.44 & 12.87 & Abiencapital & 5.57 & 9.24 & Ftierratemp2 & 3.83 & 11.30 \\
\hline Afrtve1 & 2.08 & 9.82 & Abienconsdur & 18.17 & 9.98 & Ftierratemp3 & 3.20 & 11.49 \\
\hline Aotroscult1 & 1.50 & 9.75 & Aconstruc & 2.00 & 9.58 & Ftierratemp4 & 3.70 & 11.74 \\
\hline Amaíz2 & 1.67 & 10.83 & Aservprof & 59.36 & 9.92 & Ftierratemp5 & 1.56 & 10.15 \\
\hline Atrigo2 & 1.20 & 14.51 & Aotroserv & 37.54 & 11.35 & Ftierrairrig1 & 4.88 & 8.97 \\
\hline Afrijol2 & 1.59 & 11.38 & Acomytransp & 66.19 & 10.94 & Ftierrairrig2 & 3.47 & 6.89 \\
\hline Aotrosgranos 2 & 1.67 & 15.32 & Cmaiz & 4.87 & 6.91 & Ftierrairrig3 & 2.75 & 10.16 \\
\hline Afrtve2 & 1.74 & 10.35 & Ctrigo & 3.08 & 9.17 & Ftierrairrig4 & 1.45 & 11.65 \\
\hline Aotroscult2 & 1.82 & 10.41 & Cfrijol & 1.52 & 8.86 & Ftierrairrig5 & 3.51 & 10.79 \\
\hline Amaíz3 & 2.07 & 10.57 & Cotrosgranos & 2.89 & 9.71 & Fagua1 & 1.02 & 2.00 \\
\hline Atrigo3 & 1.17 & 14.12 & Cfrtve & 4.14 & 9.36 & Fagua2 & 1.01 & 2.00 \\
\hline Afrijol3 & 1.13 & 11.16 & Cotroscult & 5.17 & 7.37 & Fagua3 & 1.00 & 2.00 \\
\hline Aotrosgranos 3 & 1.58 & 13.64 & Cgansilvpe & 8.82 & 9.84 & Fagua4 & 1.00 & 2.00 \\
\hline Afrtve3 & 1.83 & 11.15 & Cprolac & 6.78 & 10.10 & Fagua5 & 1.06 & 2.00 \\
\hline Aotroscult3 & 1.87 & 10.67 & Cfrtvepre & 1.91 & 10.71 & Fcapital & 87.14 & 8.06 \\
\hline Amaíz4 & 1.52 & 11.38 & Ctrigomanuf & 4.31 & 9.68 & Hurbpob & 13.60 & 10.90 \\
\hline Atrigo4 & 1.01 & 11.95 & Cmaizmanuf & 9.18 & 12.19 & Hurbmedia & 41.46 & 10.62 \\
\hline Afrijol4 & 1.11 & 12.34 & Cazumanuf & 2.76 & 8.05 & Hurbricos & 51.67 & 9.77 \\
\hline Aotrosgranos 4 & 1.04 & 11.47 & Cotrosalim & 19.38 & 10.17 & Hrurpob1 & 3.08 & 10.18 \\
\hline Afrtve4 & 1.60 & 11.02 & Cmanuflig & 17.38 & 7.47 & Hrurpob2 & 7.91 & 10.83 \\
\hline Aotroscult4 & 1.86 & 11.51 & Cbieninter & 14.95 & 7.19 & Hrurpob3 & 4.53 & 10.63 \\
\hline Amaíz5 & 1.00 & 10.48 & Cbiencapital & 10.36 & 5.07 & Hrurpob4 & 7.43 & 10.77 \\
\hline Atrigo5 & 1.00 & 11.50 & Cbienconsdur & 22.48 & 8.62 & Hrurpob5 & 1.46 & 10.26 \\
\hline Afrijol5 & 1.00 & 11.05 & Cconstruc & 1.00 & 10.55 & Hrurmedia1 & 4.36 & 6.74 \\
\hline Aotrosgranos5 & 1.07 & 12.75 & Cservprof & 58.81 & 10.84 & Hrurmedia2 & 6.25 & 10.52 \\
\hline Afrtve5 & 1.04 & 10.78 & Cotroserv & 37.50 & 11.92 & Hrurmedia3 & 7.30 & 10.79 \\
\hline Aotroscult5 & 1.03 & 10.57 & Ccomytransp & 65.19 & 11.93 & Hrurmedia4 & 6.03 & 10.72 \\
\hline Agansilvpe & 7.66 & 10.46 & Ftrabprof & 20.24 & 10.70 & Hrurmedia5 & 2.46 & 8.39 \\
\hline Agansilvpe5 & 1.82 & 10.10 & Ftrabagricola1 & 2.53 & 9.50 & Hrurrico1 & 8.28 & 7.97 \\
\hline Aprolac & 6.49 & 11.24 & Ftrabagricola2 & 3.61 & 11.45 & Hrurrico2 & 6.14 & 5.89 \\
\hline Afrtvepre & 2.75 & 10.58 & Ftrabagricola3 & 2.91 & 11.21 & Hrurrico3 & 9.57 & 9.16 \\
\hline Atrigomanuf & 4.46 & 10.82 & Ftrabagricola4 & 2.77 & 11.74 & Hrurrico4 & 4.42 & 10.65 \\
\hline Amaizmanuf & 10.18 & 11.19 & Ftrabagricola5 & 1.93 & 10.66 & Hrurrico5 & 6.92 & 9.30 \\
\hline \multirow{2}{*}{ Aazumanuf } & \multirow{2}{*}{2.95} & \multirow{2}{*}{9.95} & \multirow{2}{*}{ Ftrabemp } & \multirow{2}{*}{29.27} & \multirow{2}{*}{10.84} & Rentr & 6.10 & 1.00 \\
\hline & & & & & & Empresas & 83.72 & 7.43 \\
\hline
\end{tabular}

Fuente: Elaboración propia con base en la MCs 2002. 
Gráfica 1. Multiplicadores contables

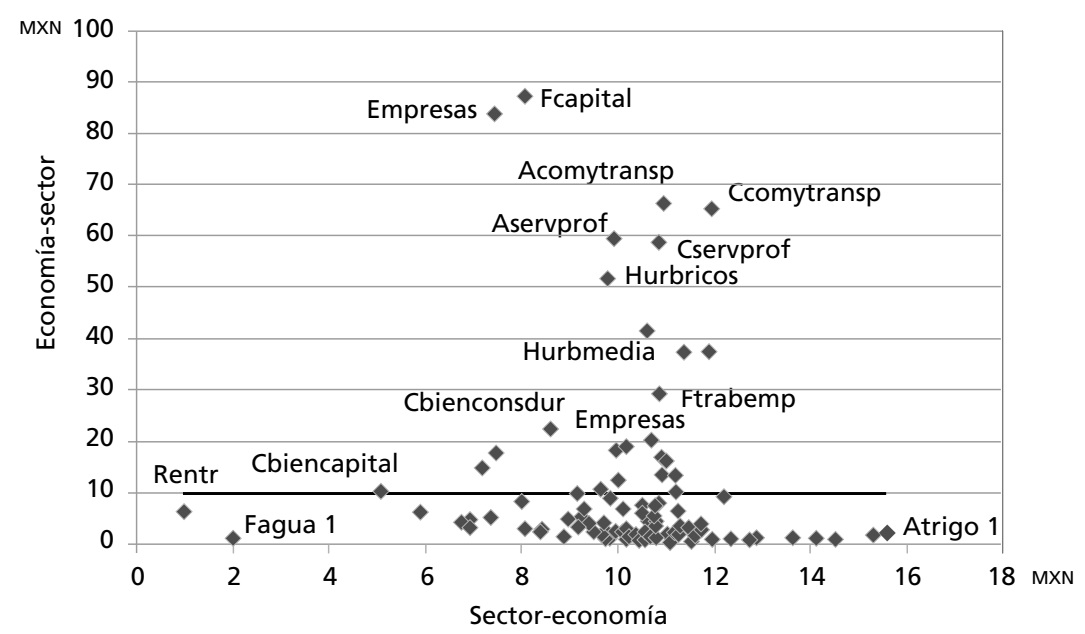

Fuente: Elaboración propia con base en la MCs 2002.

rango de MXN 12.75 a MXN 15.32. Estas actividades afectan en mayor medida a la economía por su relativamente elevada demanda de insumos nacionales y el mayor pago a los factores productivos. Además, el hecho de que el valor del multiplicador sea el más alto indica que estos sectores son los más vinculados a la estructura productiva nacional.

Por su parte, las de menor impacto son las cuentas asociadas principalmente al factor productivo agua de las cinco regiones rurales y su cuenta asociada de usuarios, con efectos multiplicativos en el rango de MXN 1 a MXN 2. También las cuentas de bienes, en especial, maiz, otros cultivos, frijol y manufactura de azúcar. La reducida producción doméstica de maíz amarillo y la importación de volúmenes crecientes para satisfacer los requerimientos de la actividad ganadera y la industria de botanas contribuyen a la menor vinculación con la actividad productiva doméstica. En este grupo de menor impacto, también se hallan las cuentas bienes de manufactura ligera, de consumo duradero, bienes intermedios y bienes de capital, que comprenden sectores que cuentan con una presencia importante de plantas maquiladoras muy poco integradas a la economía nacional, es decir, gran parte de los insumos intermedios se importan, se ensamblan en el país o se realiza algún proceso de manufactura, y se exportan casi en su totalidad. Los valores de los efectos multiplicativos de las diferentes categorías de la cuenta bienes anteriormente mencionados se encuentran en el rango 
de MXN 5.07 a MXN 8.86. El menor multiplicador sugeriría que estos sectores son los menos vinculados o los más aislados del aparato productivo doméstico en relación al resto de los sectores de bienes.

Por otra parte, una disminución unitaria en el ingreso de los hogares tiene un efecto variable según su tipo. Para los hogares pobres y de clase media de las distintas regiones rurales (excepto la clase media de las regiones Norte y Río Bravo), así como de la urbana, tiene efectos multiplicadores en el rango de MXN 10.18 a MXN 10.90, mientras que para los hogares ricos de las regiones rurales y urbana el rango va de MXN 5.89 a MXN 9.77. Los resultados de este trabajo indican que los hogares pobres y de clase media, tanto de las regiones rurales como de la urbana, consumen, en promedio. bienes con mayor contenido nacional e intensivos en mano de obra; por lo tanto, el impacto de su consumo en la economía nacional es mayor en comparación con los hogares ricos. Éstos tienen una mayor propensión media al consumo de bienes importados o con mayor contenido importado e intensivo en tecnología, por lo tanto, el impacto de su consumo en la economía local es más reducido. ${ }^{19}$

En cuanto a los efectos economía-sector, la contracción de la economía, tomada en su conjunto, afecta los ingresos de las cuentas de las instituciones, en especial, de los hogares urbanos de clase media y ricos y de las empresas, con efectos multiplicadores de MXN 41.46, MXN 51.67 y MXN 83.72, respectivamente. De las actividades, sobresale el efecto multiplicador de servicios profesionales, comercio y transporte, y las mismas pero correspondientes a las cuentas bienes, con efectos multiplicativos en el rango de MXN 58.81 a MXN 66.19. El decrecimiento económico afecta este tipo de servicios y desestimula el comercio local.

${ }^{19}$ Este resultado implicaría también que lo contrario es válido. Esto es, cada peso adicional recibido por los hogares pobres y de clase media tendría mayores efectos multiplicadores en la economía que el recibido por los hogares ricos. Y este peso extra podría ser de remesas, dado que los efectos multiplicadores de éstas no son estructuralmente diferentes a los de cualquier otro ingreso (Canales, 2008). Es decir, que un peso adicional por remesas recibido por los hogares pobres y de clase media tendría mayores efectos multiplicadores en la economía que si el mismo peso fuera recibido por los hogares ricos. Esto difiere de los hallazgos de otros investigadores (Taylor et al., 1996). Los resultados del análisis de multiplicadores contables permiten concluir que el impacto sobre la economía está en función del nivel socioeconómico de los hogares, como se demuestra en este trabajo, y no de la región donde residen (rural o urbana), a diferencia de lo encontrado por Taylor et al. (1996) en el sentido de que "las remesas producen los mayores efectos multiplicadores cuando fluyen a los hogares rurales cuyo consumo y patrones de gasto favorecen bienes producidos domésticamente con tecnologías de producción intensivas en mano de obra y pocos insumos importados. Cuando las remesas fluyen a hogares urbanos, el dinero se fuga fuera del país en la forma de bienes importados". 
La cuenta del factor capital, con un multiplicador de MXN 87.14, se ve afectada por una actividad económica reducida, lo que se traduce en menores retribuciones a este factor. Los hogares dueños de capital, así como los relacionados con las actividades de servicios profesionales y de comercio y transporte, es decir, los hogares urbanos y de nivel socioeconómico medio y elevado, son los más perjudicados por el decrecimiento de la actividad productiva.

La disminución en la actividad económica perjudica a los hogares y a la actividad, en general, de las localidades urbanas, donde principalmente se ubican establecimientos comerciales y grandes empresas de transporte. En especial, los hogares urbanos de clase media y ricos son los más vinculados a los mercados de trabajo y de bienes y, por lo tanto, una contracción de la economía los afecta en mayor medida. Los hogares pobres están menos vinculados a los distintos mercados de la economía nacional, ya sea porque son de autoconsumo (y venden muy poco de lo que producen) o porque se emplean por cuenta propia en la economía informal.

La mayoría de las cuentas de actividades y factores correspondientes a las cinco regiones rurales tienen multiplicadores economía-sector muy reducidos, con valores que van de MXN 1 a MXN 4.88. La economía rural se ve poco afectada por el decrecimiento de la economía nacional. Las cuentas de actividades (producción agrícola) y factores (trabajo agrícola, tierra de temporal e irrigada) en las regiones rurales tienen mayores multiplicadores sector-economía y menores multiplicadores economía-sector. Lo mismo sucede para el sector de ganadería, tanto en la región Río Bravo en el resto del país. La economía se ve afectada gravemente por la disminución de dichas cuentas, pero, por el contrario, la contracción de la economía no afecta gravemente a las cuentas de actividades y factores rurales y ganadería. Por su parte, las cuentas de bienes de manufactura ligera, de consumo duradero, bienes intermedios y bienes de capital de la región urbana presentan el efecto contrario. En cuanto a los factores de producción, los de las regiones rurales (trabajo agrícola, tierra de temporal y de riego) tienen efectos sector-economía más fuertes que los efectos economía-sector. Lo contrario sucede para el factor capital..$^{20}$ Los hogares urbanos son los más afectados por el decrecimiento de la actividad económica en comparación con los rurales.

${ }^{20}$ Estos resultados son parecidos a los encontrados por Barceinas, Crowe y Yunez-Naude (1997), aunque con algunas diferencias. Según estos autores, para las cuentas de actividades y mercancías (bienes) "todos los componentes de la producción agropecuaria tienen índices hacia atrás [sector-economía] más fuertes que sus índices hacia adelante [economía-sector], es decir, una expansión en la demanda exógena para la producción agropecuaria crea un estímulo mayor en la 


\section{SimULACIÓN BASADA EN EL MODELO DE MULTIPLICADORES CONTABLES}

Se simuló una reducción de $10 \%$ en el valor de las remesas internacionales que reciben los hogares mexicanos; es decir, una reducción de MXN 9.492 billones, ${ }^{21}$ equivalente a $0.152 \%$ del PIB $\left(0.13 \%\right.$, con cifras a precios corrientes del INEGI. ${ }^{22}$ El interés se centra en realizar un análisis acerca de las consecuencias de tal situación en el nivel de actividad económica, la remuneración o pagos a factores productivos y los ingresos de los hogares. Los resultados se presentan en el cuadro $4 .{ }^{23}$

Los sectores económicos más afectados en términos relativos son la producción de trigo y otros granos los cuales forman parte de las cuentas de actividades (para las cinco regiones rurales) y de bienes; la reducción en el envío de remesas hace caer de $0.89 \%$ a $1.6 \%$ los ingresos de tales cuentas. La disminución de los ingresos de los hogares receptores de remesas provoca un efecto ingreso desfavorable al consumo de alimentos derivados del trigo, por lo cual, indirectamente, reduce la demanda industrial del grano y, por lo tanto, desincentiva su producción en las regiones rurales. La producción de trigo se basa predominantemente en el riego de grandes extensiones de tierra, por lo que una baja en la actividad económica disminuye el pago en $0.43 \%$ al factor agua en las regiones Norte (Sonora, Baja California) y Centro (Guanajuato), que es donde se concentra su producción.

economía mexicana que el impulso recibido por dicho sector cuando hay una expansión generalizada de tal economía, y lo contrario sucede para los sectores urbanos. En cuanto a los factores de producción se concluye que, para todos los tipos de capital, los índices hacia adelante son más fuertes que los índices hacia atrás y lo contrario sucede con los índices de todos los tipos de trabajo".

${ }^{21}$ Esta cantidad es equivalente a USD 981.450 millones a un tipo de cambio promedio diario de MXN 9.67 por dólar (cifras del Fondo Monetario Industrial). En 2008, las remesas disminuyeron en una cantidad ligeramente menor (USD 914 millones) con respecto al nivel previo anual, como consecuencia de la crisis financiera y económica mundial.

${ }^{22}$ Véase en INEGia (s.f.) el cuadro "PIB México precios corrientes por trimestres y anuales 1993-2014. Cifras originales. Millones de pesos".

${ }^{23}$ La simulación tuvo como fin realizar un ejercicio académico para probar la capacidad de predicción de la MCS 2002. Dicho ejercicio se basa en la estructura de la economía en 2002 y, por lo tanto, simula los efectos de una disminución de las remesas internacionales en dichas condiciones. En el uso de modelos multisectoriales son comunes las aplicaciones que consideran un marco temporal de cinco años como periodo válido para proyectar los resultados de las simulaciones. Por ello, los efectos reales del descenso de las remesas en el año 2008 se comparan con los predichos por el modelo. 
Cuadro 4. Impacto de la disminución de $10 \%$ en las remesas

\begin{tabular}{|c|c|c|c|c|c|}
\hline Cuenta & Porcentaje & Cuenta & Porcentaje & Cuenta & Porcentaje \\
\hline Amaiz1 & -0.44 & & & & \\
\hline Atrigo1 & -1.15 & & & & \\
\hline Afrijol1 & -0.32 & Cmaiz & -0.44 & Ftrabprof & -0.31 \\
\hline Aotrosgranos 1 & -1.30 & & & Ftrabagricola1 & -0.42 \\
\hline Afrtve1 & -0.32 & Ctrigo & -1.22 & Ftrabagricola2 & -0.34 \\
\hline Aotroscult1 & -0.25 & & & Ftrabagricola3 & -0.39 \\
\hline Amaíz2 & -0.43 & Cfrijol & -0.32 & Ftrabagricola4 & -0.33 \\
\hline Atrigo2 & -1.00 & & & Ftrabagricola5 & -0.40 \\
\hline Afrijol2 & -0.32 & Cotrosgranos & -1.60 & Ftrabemp & -0.31 \\
\hline Aotrosgranos 2 & -0.97 & & & Ftrabobr & -0.27 \\
\hline Afrtve2 & -0.32 & Cfrtve & -0.32 & Ftrabnocap & -0.32 \\
\hline Aotroscult2 & -0.25 & & & & \\
\hline Amaíz3 & -0.44 & Cotroscult & -0.25 & & \\
\hline Atrigo3 & -1.04 & & & & \\
\hline Afrijol3 & -0.32 & Cgansilvpe & -0.40 & Ftierratemp1 & -0.42 \\
\hline Aotrosgranos3 & -1.25 & & & Ftierratemp2 & -0.49 \\
\hline Afrtve3 & -0.32 & Cprolac & -0.43 & Ftierratemp3 & -0.43 \\
\hline Aotroscult3 & -0.25 & & & Ftierratemp4 & -0.32 \\
\hline Amaíz4 & -0.43 & Cfrtvepre & -0.25 & Ftierratemp5 & -0.62 \\
\hline Atrigo4 & -1.10 & & & & \\
\hline Afrijol4 & -0.32 & Ctrigomanuf & -0.41 & & \\
\hline Aotrosgranos4 & -1.47 & & & & \\
\hline Afrtve4 & -0.32 & Cmaizmanuf & -0.44 & Ftierrairrig1 & -0.48 \\
\hline Aotroscult4 & -0.25 & & & Ftierrairrig2 & -0.41 \\
\hline Amaíz5 & -0.35 & Cazumanuf & -0.38 & Ftierrairrig3 & -0.37 \\
\hline Atrigo5 & -1.05 & & & Ftierrairrig4 & -0.29 \\
\hline Afrijol5 & 0.00 & Cotrosalim & -0.38 & Ftierrairrig5 & -0.47 \\
\hline Aotrosgranos5 & -0.89 & & & & \\
\hline Afrtve5 & -0.31 & Cmanuflig & -0.25 & & \\
\hline Aotroscult5 & -0.25 & & & & \\
\hline Agansilvpe & -0.40 & Cbieninter & -0.12 & Fagua1 & -0.43 \\
\hline Agansilvpe 5 & -0.40 & & & Fagua2 & -0.43 \\
\hline Aprolac & -0.43 & Cbiencap & -0.05 & Fagua3 & 0.00 \\
\hline Afrtvepre & -0.25 & & & Fagua4 & 0.00 \\
\hline Atrigomanuf & -0.41 & Cbienconsdur & -0.16 & Fagua5 & 0.00 \\
\hline Amaizmanuf & -0.44 & & & & \\
\hline Aazumanuf & -0.38 & Cconstr & 0.00 & & \\
\hline Aotrosalim & -0.38 & & & & \\
\hline Amanuflig & -0.25 & Cservprof & -0.30 & Fcapital & -0.26 \\
\hline Abieninter & -0.12 & & & & \\
\hline Abiencap & -0.05 & Cotroserv & -0.37 & Hogares & -0.45 \\
\hline Abienconsdur & -0.16 & & & & \\
\hline Aconstr & 0.00 & Ccomytransp & -0.34 & Rentr & -0.43 \\
\hline Aservprof & -0.30 & & & & \\
\hline Aotroserv & -0.37 & & & Empresas & -0.25 \\
\hline Acomytransp & -0.34 & & & & \\
\hline
\end{tabular}

Fuente: Elaboración propia con base en la MCs 2002. 
Los ingresos de los hogares (rurales y urbanos, en su conjunto) bajan $0.45 \%$, debido a los efectos directos e indirectos que tiene la disminución de remesas sobre la economía. ${ }^{24}$ Las remuneraciones de los factores disminuyen: las de los trabajadores agrícolas en $0.38 \%$, en promedio; las de los trabajadores urbanos (profesionistas, empleados, obreros e informales) en $0.30 \%$, en promedio; la renta de la tierra de temporal, en $0.46 \%$, así como la de la tierra de riego, en $0.40 \%$, y el factor capital, $0.26 \%$. Las reducciones ligeramente mayores, se presentan en los factores de las regiones Norte y Río Bravo.

El sector maiz, en las cuentas de bienes y de actividades, tiene una reducción de $0.43 \%$ a $0.44 \%$. La ganadería-silvicultura-pesca en todas las regiones rurales se ve afectada en $0.40 \%$, mientras que la producción urbana de productos lácteos sufre una caída de $0.43 \%$, en promedio. La producción de frijol y frutas y vegetales de las cinco regiones rurales (excepto el frijol en la región Río Bravo) disminuye $0.32 \%$. La actividad otros cultivos decae $0.25 \%$.

En cuanto a la producción de sectores nacionales, baja la manufactura de trigo $(0.41 \%)$ y la manufactura de azúcar y otros alimentos $(0.38 \%)$. El sector otros servicios tuvo una afectación de $0.37 \%$ y la prestación de servicios profesionales se vio deprimida en $0.30 \%$; el comercio y transporte disminuyó en $0.34 \%$, en promedio. El factor agua en las regiones 3 (Suroeste), 4 (Sureste) y 5 (Río Bravo), y el sector de la construcción son los menos afectados con disminuciones muy cercanas a cero, así como la producción de bienes de capital (0.05\%), intermedios $(0.12 \%)$ y de consumo duradero $(0.16 \%)$.

El PIB a precios básicos desciende $0.28 \%$ como resultado de la disminución en 10\% del envío de remesas. Es decir, cada MXN 33900 millones menos en remesas reduce en $1 \%$ el PIB.$^{25}$ Los efectos relativos, directos e indirectos, del descenso en las remesas fueron mayores en la producción sectorial de la agricultura-ganadería, manufactura alimentaria, comercio, servicios y transporte, y menores en los sectores de la construcción, producción de bienes de capital,

\footnotetext{
${ }^{24}$ Aguayo et al. (2009) proporcionan evidencia respecto a los impactos diferenciados por tipo de hogar. El estudio citado simula un incremento unitario en las remesas internacionales y sus impactos en los hogares a nivel decil de ingreso, sin distinguir entre regiones rurales y urbanas. Estos autores encontraron que los hogares de los tres deciles más ricos son los más beneficiados por la inyección exógena de las remesas. Lo contrario también es válido, en el sentido de que los hogares de los tres deciles más ricos serían los más afectados ante un descenso unitario en ellas.

${ }^{25}$ El multiplicador de las remesas asciende a MXN 1.84. Por cada peso adicional recibido (o descontado) por concepto de remesas, el PIB mexicano aumenta (o disminuye) MXN 1.84. La magnitud del multiplicador es consistente con la pequeña participación de las remesas en el PIB de la economía mexicana, alrededor de $2 \%$.
} 
intermedios y de consumo duradero. ${ }^{26}$ Además, la mayor parte de la afectación corresponde a la región urbana $(0.27 \%)$ y marginalmente a las rurales $(0.01 \%)$. La región rural más afectada es la Centro y la menos afectada es la Río Bravo

Los efectos directos e indirectos y su impacto final en la producción doméstica están basados en los supuestos del modelo de multiplicadores contables, los cuales condicionan los resultados de la presente investigación. Dichos supuestos son que los precios no se ajustan a la baja ni al alza y el gasto de empresas y consumidores disminuye en la misma proporción que su ingreso (la elasticidad gasto es unitaria), los cuales hacen que los multiplicadores contables sobreestimen los efectos de una reducción en los ingresos de las cuentas exógenas.

\section{ANÁlisis ESTRUCTURAL DE TRAYECTORIAS}

De acuerdo con Defourny y Thorbecke (1981), el análisis estructural de trayectorias es una forma de descomposición de los multiplicadores contables, a través de la cual es posible identificar las diferentes rutas de transmisión de los impactos exógenos sobre las cuentas endógenas y que parte de identificar una trayectoria elemental, con un polo de origen $i$ y un polo de destino $j$, esto es, $(i, \ldots, j)$. Estos autores plantean que la influencia ejercida por $i$ sobre $j$, distingue los siguientes elementos:

a) Influencia directa. Es el cambio en el ingreso de $j$ debido al cambio de una unidad en $i$. Es igual al producto de las propensiones medias de cada par de cuentas adyacentes que constituyen la trayectoria elemental. $I^{d}{ }_{(i \rightarrow j)}=I_{(i, x, y, j)=}^{d} a_{x i} a_{y x} a_{j y}$

\footnotetext{
${ }^{26}$ Las estimaciones de este trabajo son consistentes con la evidencia empírica disponible sobre los efectos de la Gran Recesión estadounidense sobre la economía mexicana (Mejía-Reyes y DíazCarreño, 2015). En el modelo econométrico estimado por los autores, las remesas (como porcentaje del PIB estatal) tuvieron un coeficiente negativo y significativo sobre la producción industrial de las entidades federativas. Dicho hallazgo sugiere que mientras mayor sea la exposición de la economía a impactos externos en las remesas, mayor será el descenso en la producción industrial. Aunque no se desagregan los efectos a nivel rama de la producción industrial, es claro que los mayores efectos en la industria corresponden a la manufactura de alimentos más que a la de bienes intermedios y de bienes de capital, dado que una proporción significativa de las remesas se destina al gasto en bienes y servicios de consumo final (Arroyo y Berumen, 2000). Por otra parte, MejíaReyes y Díaz-Carreño (2015) mencionan que las remesas no fueron relevantes para explicar el descenso en la producción total de la economía, dada la baja participación de las remesas en el PIB estatal.
} 
b) Influencia total. Es el cambio en el ingreso de $j$ debido al cambio de una unidad en $i$ incluyendo no sólo los efectos directos si no también indirectos. Estos últimos ocurren cuando los polos que forman la trayectoria elemental están vinculados a otros polos y otras trayectorias, creando circuitos que amplifican los efectos directos. $I_{(i \rightarrow j)}^{t}=I_{(i \rightarrow j)}^{d} M_{p^{p}}$, donde $M_{p}$ es el efecto ampliado y es un cociente de determinantes. El numerador de $M_{p}$ es el determinante de la matriz identidad menos la matriz de propensiones medias, a la cual se le ha eliminado los polos que constituyen la trayectoria elemental. El denominador es el determinante de la misma matriz, pero incluyendo los polos que conforman la trayectoria elemental.

c) Influencia global. Es una medida de los efectos totales sobre el ingreso de $j$ debidos a una inyección de una unidad en el ingreso de $i$. Incluye la influencia directa transmitida por todas las trayectorias elementales que tienen a $i$ como polo de origen y a $j$ como polo de destino y a las trayectorias como un todo, es decir, los circuitos que forman entre todas ellas. $I_{(i \rightarrow j)}^{\mathrm{g}}=m_{a j j^{\prime}}$ donde $m_{a j i}$ es el $(j, i)$ elemento de la matriz de multiplicadores contables.

En este trabajo, es de especial interés identificar la ruta de transmisión de los efectos de una disminución de las remesas internacionales que reciben los hogares rurales, como polo de origen, sobre los ingresos de los distintos tipos de trabajadores (agrícolas, obreros, profesionales, empleados y sin instrucción). La disminución en los ingresos de los hogares rurales, siguiendo la trayectoria circular del ingreso, se traduciría en primer lugar en una baja del gasto de consumo $\mathrm{y}$, por lo tanto, en las ventas de las empresas de diferentes sectores y en el empleo, en este orden, generando efectos directos, indirectos y globales que fluyen hacia los circuitos de interés.

En el cuadro 5 se observa que la disminución de los ingresos de los hogares rurales afecta globalmente en mayor medida al empleo urbano, en especial a las remuneraciones de los empleados y los profesionistas. Esto coincide con los hallazgos de autores como Arroyo y Berumen (2000), Adelman y Taylor (1990) y Taylor et al. (1996). ${ }^{27}$ Por ejemplo, cada peso menos de remesas a los hogares

${ }^{27}$ Taylor et al. (1996, p. 201) sostienen que "muchos de los beneficios de las remesas fluyen a los hogares que no son los que las reciben de manera directa... Cuando un hogar rural usa las remesas para comprar bienes manufacturados en el sector urbano, los efectos multiplicadores de segunda ronda del ingreso se mueven al sector urbano"... "\$1 dólar en remesas genera un aumento de $\$ 0.29$ dólares en el ingreso de los pequeños agricultores y \$0.38 dólares en el ingreso de los 


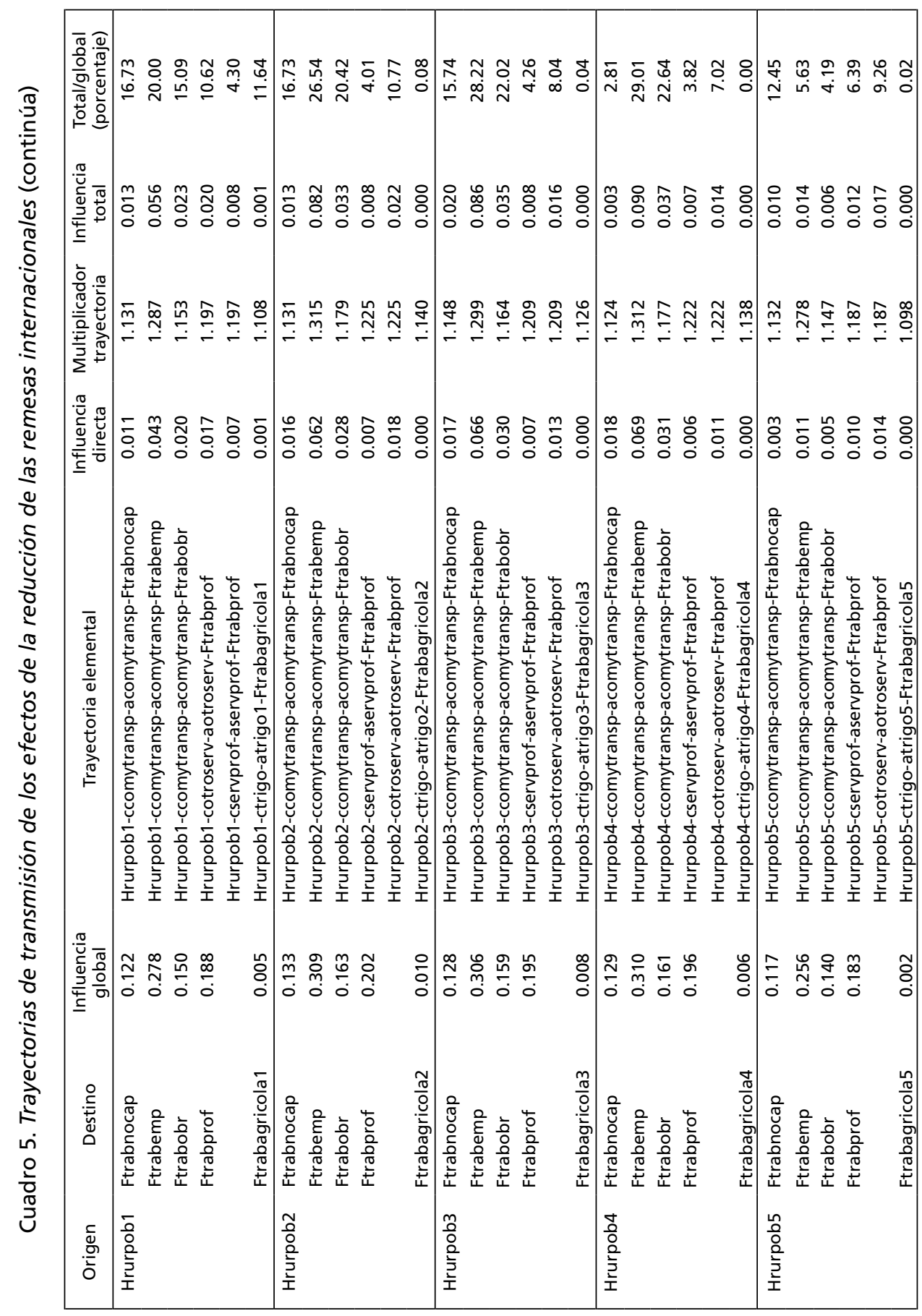


126 ECONOMÍA: TEORÍA Y PRÁCTICA • Nueva Época, número 45, julio-diciembre 2016

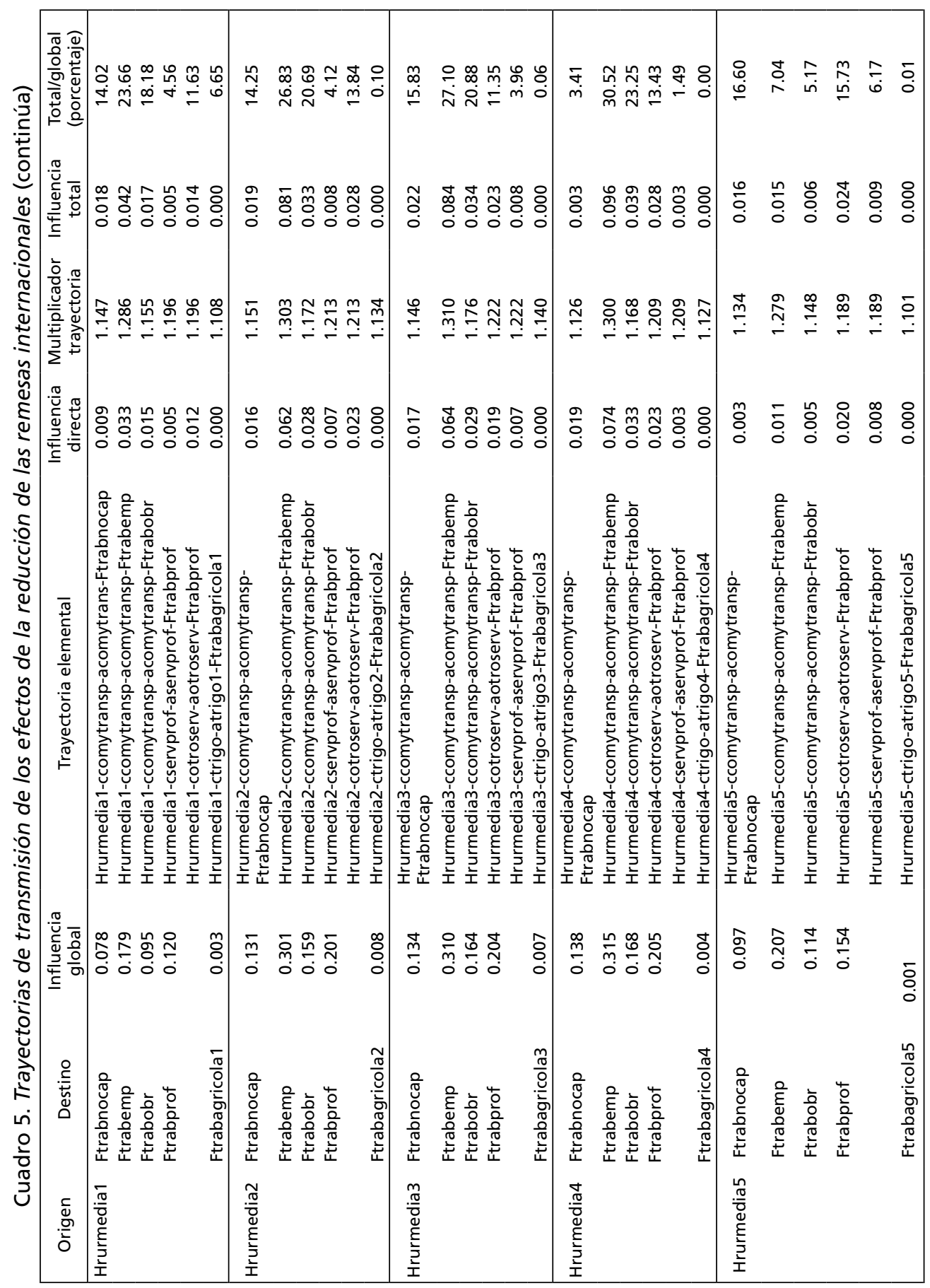




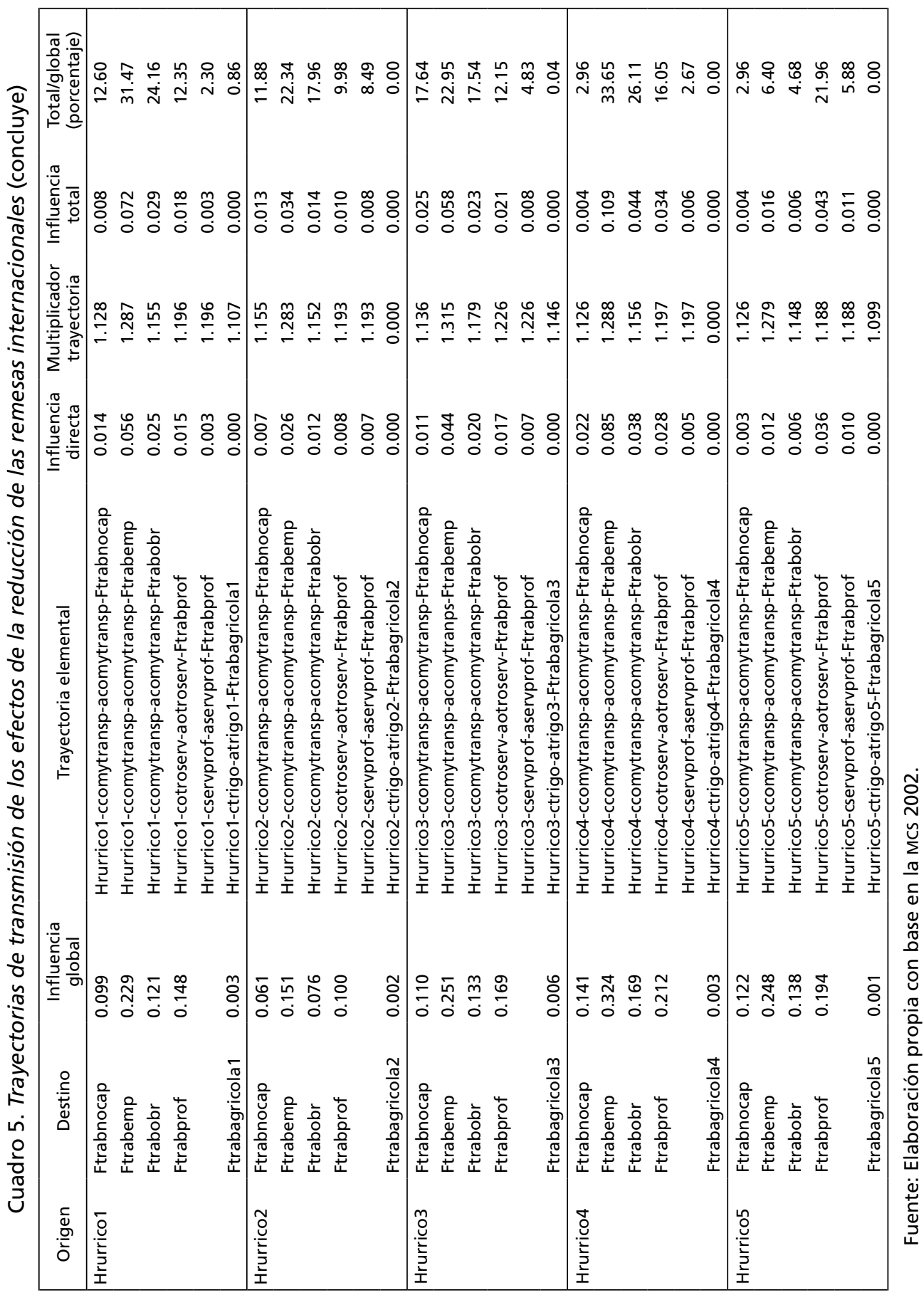


ricos de la región rural 2 (Centro) disminuye globalmente los ingresos de los empleados urbanos en MXN 0.151 pesos y $22.34 \%$ de dicho efecto proviene del sector comercio y transporte. ${ }^{28} \mathrm{~A}$ su vez, cada peso de menos en las remesas a los hogares pobres de la región rural 4 (Sureste) disminuye globalmente los ingresos de los empleados urbanos en MXN 0.31 y el sector de comercio y transporte en la región urbana representa $22.34 \%$ de dicho efecto. Por otra parte, cada peso restado a las remesas de los hogares ricos de la región rural 2 (Centro) disminuye globalmente los ingresos de los profesionistas urbanos en MXN 0.1 pesos y el sector otros servicios representa $9.98 \%$ de dicho efecto, mientras que cada peso menos en las remesas a los hogares de clase media de la región rural 4 (Sureste) disminuye globalmente los ingresos de los profesionistas en MXN 0.205 y el sector otros servicios representa $13.43 \%$ de tal efecto. Por otra parte, la influencia global en el empleo rural (trabajo agrícola) es muy reducida, en el rango de MXN 0.001 a MXN 0.010 .

\section{CONCLUSIONES}

La construcción de una MCS es exigente, pero relevante, ya que proporciona la base de datos necesaria para realizar estudios de impacto a partir de modelos multisectoriales que capturan los posibles efectos directos e indirectos de choques exógenos sobre una economía y sus grupos sociales. Uno de los problemas para elaborar la MCs 2002 de México fue la ausencia de datos, aun cuando el objetivo fuera la actualización de una matriz nacional, que sólo requiere información sobre los totales de columna y de fila. Además, los datos publicados por distintas fuentes oficiales no son compatibles debido a que los métodos de captación difieren, según el objetivo del programa al cual están destinados. Por ejemplo, en el caso de las estadísticas de comercio exterior, se emplearon los registros administrativos de las aduanas mexicanas, mientras que para obtener las estadísticas de ingreso y gasto de los hogares, generalmente se aplican encuestas a una muestra representativa a nivel nacional.

De lo anterior, resulta que la matriz no está balanceada y se hizo necesario balancearla usando el método de entropía, el cual es un método de estimación

trabajadores rurales y 1.11 dólares de incremento en el ingreso de los hogares de trabajadores urbanos a pesar del hecho de que la mayor parte de las remesas no proviene de este último grupo". Nótese que el análisis que ellos realizan, sin embargo, tiene como destino los hogares clasificados según condición de trabajo principal.

${ }^{28}$ Otros sectores de la economía explican el restante $77.66 \%$ de la disminución. 
contemporáneo y flexible, que permite resolver éstos y otros inconvenientes a partir del uso de programas computacionales. Con el método de entropía es posible actualizar y balancear matrices; sin embargo, antes de hacer esto último, es necesario asegurarse de organizar la MCS de tal forma que sea lo más consistente posible con la matriz que sirvió de base para la actualización. En especial, se deben mantener los mismos supuestos que se emplearon en la construcción de la MCS original, ya que de lo contrario, habrá problemas con el programa GAMS, usado en esta investigación.

Una vez resuelto lo anterior, se puede estimar los multiplicadores contables del modelo multisectorial de la economía mexicana. Los resultados indican que la economía se ve afectada directa e indirectamente en mayor medida por la contracción en la producción y en el valor agregado de las actividades de las distintas regiones rurales. Se puede decir que esas cuentas son las que tienen los vínculos más fuertes con el resto de los sectores. Al contrario, el decremento de la economía no influye de manera importante en la contracción de las cuentas de producción (actividades y factores) de las regiones rurales, ya que las actividades más perjudicadas directa e indirectamente son aquellas asociadas al sector urbano como las de servicios profesionales, comercio y transportes.

Los hogares pobres y de clase media tienen mayores efectos multiplicadores que los hogares ricos, independientemente de que sean rurales o urbanos, ya que consumen, en promedio, bienes con un mayor contenido nacional e intensivos en mano de obra. Por lo tanto, el impacto de su consumo en la economía nacional es mayor en comparación con los hogares ricos. Éstos tienen una mayor propensión media al consumo de bienes importados, o con mayor contenido importado, e intensivos en tecnología, por lo que el impacto de su consumo en la economía local es más reducido

El PIB desciende $0.28 \%$ cuando las remesas internacionales disminuyen $10 \%$, es decir, por cada MXN 33900 millones menos en remesas, el PIB baja 1\%. La mayor parte de esta afectación recae en la región urbana $(0.27 \%)$ y marginalmente en las rurales $(0.01 \%)$. De éstas, la más afectada es la Centro y la menos afectada, la Río Bravo.

Las actividades agrícolas más afectadas directa e indirectamente por la reducción de las remesas son las de la producción de trigo y otros granos, así como los pagos a los factores que intervienen en éstas. Lo anterior se da, sobre todo con el factor agua de riego en las regiones rurales Norte y Centro, que concentran el cultivo de estos granos. Lo anterior se debe a que estos productos agrícolas son más sensibles a las variaciones en los ingresos de los hogares rura- 
les y urbanos -como la causada inicialmente por la disminución de las remesasen comparación con otros cultivos.

Los efectos relativos directos e indirectos del descenso en las remesas fueron mayores sobre la producción sectorial de la agricultura-ganadería, manufactura alimentaria, comercio, servicios y transporte, mientras que fueron menores en los sectores de la construcción, producción de bienes de capital, intermedios y de consumo duradero. Por su parte, el análisis de trayectorias de los gastos de los hogares rurales muestra que el trabajo urbano (principalmente profesionistas y empleados) ligado a los sectores comercio y transporte, otros servicios y servicios profesionales es el más afectado globalmente por la disminución de las remesas internacionales.

En general, este estudio desarrolló estimaciones del impacto de la reducción de las remesas internacionales a partir de un enfoque de multiplicadores, es decir, de un modelo multisectorial de inspiración keynesiana. Una alternativa de modelo multisectorial -que también puede construirse mediante una MCS - es el de equilibrio general, de inspiración neoclásica. Ambos son representaciones estilizadas de una economía, es decir, que representan situaciones de frontera; por ejemplo, el primero con precios fijos y desempleo; el segundo, con pleno empleo y con precios relativos variantes.

\section{Anexo 1. Cuentas de la mCS 2002}

La $t$ final, en la denominación que aparece entre paréntesis, adopta los siguientes valores, según el caso: $1=$ Norte; $2=$ Centro; $3=$ Suroeste; 4 = Sureste; 5 = Río Bravo.

\section{Actividades y bienes}

La $T$ inicial, en la denominación entre paréntesis, se sustituye por " $A$ " cuando se refiere a la cuenta actividad y por " $\mathrm{C}$ " cuando se refiere a la cuenta bienes. En este último caso y en otras cuentas, el valor de la $t$ final desaparece, ya que, por ejemplo, para la cuenta de bienes se presentan los sectores a nivel nacional sin distinguir por región rural.
a. Maíz (Tmaizt)
b. Trigo (Ttrigot)
c. Frijol ( $T$ frijolt)
d. Otros granos (Totrosgranost) 
$e$. Frutas y vegetales (Tfrtvet)

$f$. Otros cultivos (Totroscult $t$ )

g. Ganadería, silvicultura y pesca (Tgansilvpe) ${ }^{29}$

h. Productos lácteos (Tprolac)

$i$. Preparación de frutas y vegetales (Tfrtvepre)

$j$. Manufactura de trigo (Ttrigomanuf)

$k$. Manufactura de maíz (Tmaizmanuf)

l. Manufactura de azúcar (Tazumanuf)

$m$. Otros alimentos procesados (Totrosalim)

$n$. Manufactura ligera (Tmanuflig)

$o$. Producción de bienes intermedios (Tbiennocap)

$p$. Producción de bienes de consumo duradero (Tbienconsdur)

q. Producción de bienes de capital (Tbiencap)

$r$. Servicios profesionales ( $T$ servprof)

s. Otros servicios (Totroserv)

t. Construcción (Tconstruc)

$u$. Comercio y Transporte (Tcomytransp)

\section{Factores productivos}

a. Trabajadores profesionales (Ftrabprof)

b. Empleados (Ftrabemp)

c. Obreros (Ftrabobr)

d. Trabajadores sin instrucción o informales (Ftrabnocap)

e. Trabajadores agrícolas (Ftrabagricolat)

$f$. Tierra de temporal (Ftierratempt)

g. Tierra irrigada (Ftierrairrigt)

h. Agua (Faguat)

i. Capital (Fcapital)

\section{Hogares}

a. Urbanos pobres (Hurbpob)

b. Urbanos de clase media (Hurbmedia)

c. Urbanos ricos (Hurbricos)

${ }^{29}$ En el caso de actividades, el sector correspondiente a ganadería, silvicultura y pesca se presenta en una cuenta exclusiva para la región Río Bravo y en otra que incluye a todas las demás regiones rurales. 
d. Rurales pobres (Hrurpobt)

$e$. Rurales de clase media (Hrurmediat)

$f$. Rurales ricos (Hrurricot)

4. Asociaciones de usuarios de agua (rentr) ${ }^{30}$

5. Empresas (empresas)

6. Gobierno (gobierno)

7. Impuestos indirectos (impind)

8. Impuestos directos (impdir)

9. Ahorro (inversión)

10. Resto del mundo (restomundo)

\section{Anexo 2}

Cuadro A2. Clasificación de los trabajadores según actividad principal (continúa)

\begin{tabular}{|c|c|c|}
\hline Tipo & Clave & Descripción \\
\hline \multirow[t]{5}{*}{ 1. Profesionales } & 11 & Profesionistas \\
\hline & 12 & Técnicos \\
\hline & 13 & Trabajadores de la educación \\
\hline & 14 & Trabajadores del arte, espectáculos y deportes \\
\hline & 83 & $\begin{array}{l}\text { Trabajadores en servicios de protección y vigilancia, y fuerzas } \\
\text { armadas }\end{array}$ \\
\hline 2. Agrícolas & 41 & Trabajadores en actividades agrícolas (410) \\
\hline \multirow[t]{4}{*}{ 3. Obreros } & 52 & $\begin{array}{l}\text { Artesanos y trabajadores fabriles en la industria de la } \\
\text { transformación y trabajadores en actividades de reparación y } \\
\text { mantenimiento }\end{array}$ \\
\hline & 53 & $\begin{array}{l}\text { Operadores de maquinaria fija de movimiento continuo y } \\
\text { equipos en el proceso de fabricación industrial }\end{array}$ \\
\hline & 54 & $\begin{array}{l}\text { Ayudantes, peones y similares en el proceso de fabricación } \\
\text { artesanal e industrial y en actividades de reparación y } \\
\text { mantenimiento }\end{array}$ \\
\hline & 55 & $\begin{array}{l}\text { Conductores y ayudantes de maquinaria móvil y medios de } \\
\text { transporte }\end{array}$ \\
\hline \multirow[t]{2}{*}{ 4. Empleados } & 51 & $\begin{array}{l}\text { Jefes, supervisores y otros trabajadores de control en la } \\
\text { fabricación artesanal e industrial y en actividades de reparación } \\
\text { y mantenimiento }\end{array}$ \\
\hline & 21 & Funcionarios y directivos de los servicios público, privado y social \\
\hline
\end{tabular}

${ }^{30}$ La cuenta rentr es la que recibe los pagos del factor agua y las distribuye a la cuenta ahorro (inversión). 
Cuadro A2. Clasificación de los trabajadores según actividad principal (concluye)

\begin{tabular}{ccl}
\hline Tipo & Clave & \multicolumn{1}{c}{ Descripción } \\
\hline 61 & $\begin{array}{l}\text { Jefes de departamento, coordinadores y supervisores en } \\
\text { actividades administrativas y servicios }\end{array}$ \\
62 & $\begin{array}{l}\text { Trabajadores de apoyo en actividades administrativas } \\
\text { Comerciantes, empleados de comercio y agentes de ventas }\end{array}$ \\
\hline 5. Sin instrucción & 41 & Trabajadores en actividades ganaderas, silvícolas y de caza y \\
& 81 & Trabajadores en servicios personales en establecimientos \\
& 72 & Vendedores ambulantes y trabajadores ambulantes en servicios \\
82 & Trabajadores en servicios domésticos \\
\hline
\end{tabular}

Fuente: Harris (2002) y Encuesta Nacional de Ingreso Gasto de los Hogares, (INEGIb, s.f.), 2002.

\section{REFERENCIAS BIBLIOGRÁFICAS}

Adelman, Irma; Taylor, Edward, y Vogel, Stephen (1988), "Life in a Mexican Village: a Perspective", The Journal of Development Studies, 25 (1), pp. 5-24.

Adelman, Irma, y Taylor, Edward (1990), "Is Structural Adjustment with a Human Face Possible? The Case of Mexico", Journal of Development Studies, 26 (3), pp. 387-407.

Aguayo, Ernesto; Chapa, Joana; Ramírez, Nelly, y Rangel, Erick (2009), “Análisis de la generación y redistribución del ingreso en México a través de una matriz de contabilidad social", Estudios Económicos, 24 (núm. extraordinario), pp. 225-311.

Aragonés, Ana María, y Salgado, Uberto (2014), "El efecto de las remesas en la pobreza en comunidades de la sierra Gorda de Querétaro", en V. S. Ávila (coord.), Pobreza y sustentabilidad. Capitales en comunidades rurales, México, Ariel, pp. 41-70.

Arroyo, Jesús, y Berumen, Salvador (2000), "Efectos subregionales de las remesas de emigrantes mexicanos en Estados Unidos", Comercio Exterior, 0 (50), pp. 340-349.

Bacharach, Michael (1970), Biproportional Matrices and Input Output Change, UK, Cambridge University Press.

Banco de México (s.f.), "Sistema de Información Económica”. Consultado el 15 de marzo de 2016, en http://www.banxico.org.mx/estadisticas/index.html.

Barajas, Adolfo; Chami, Ralph; Fullenkamp, Connel; Gapen, Michael, y Montiel, Peter (2009), “Do Workers' Remittances Promote Economic Growth?”, IMF Working Paper 09/153, International Monetary Fund Institute. 
Barboza-Carrasco, Irene; Vázquez-Alvarado, Jorge, y Matus-Gardea, Jaime (2009), "Matriz de contabilidad social 2004 para México", Agrociencia, 43 (5), pp. 551-558.

Barceinas, Fernando; Crowe, Alisteir, y Yunez-Naude, Antonio (1989), "Multiplicadores contables y de precios fijos: aplicación a una matriz de contabilidad social para México (1989)", en A. Sánchez (ed.), La crisis productiva y financiera mexica$n a$, México, DF, UAM-Azcapotzalco.

Canales, Alejandro (2008), Vivir del norte. Remesas, desarrollo y pobreza en México, México, Consejo Nacional de Población.

Catrinescu, Natalia; Leon-Ledesma, Miguel; Piracha, Matloob, y Quillin, Bryce (2009), "Remittances, Institutions and Economic Growth", World Development, 37 (1), pp. 81-92.

Centro de Estudios de las Finanzas Públicas (s.f.), "Ingresos tributarios del gobierno federal". Consultado el 25 de marzo de 2016, en: http://www3.diputados.gob.mx/ camara/001_diputados/006_centros_de_estudio/02_centro_de_estudios_de_ finanzas_publicas_1/005_indicadores_y_estadisticas/01_historicas/02_ingresos _publicos_1980_2012/03_ingresos_tributarios_del_gobierno_federal _1980_2012.

Chami, Ralph; Fullenkamp, Connel, y Jahjah, Samir (2003), “Are Immigrant Remittances Flows a Source of Capital for Development?”, IMF Working Paper 03/189, International Monetary Fund Institute.

Conagua (s.f.), Sistema de Información Hidroagrícola de los Distritos de Riego, Comisión Nacional del Agua, Subdirección General de Infraestructura Hidroagrícola, Gerencia de Distritos y Unidades de Riego. Información del año agrícola 2001-2002 proporcionada por los módulos de riego.

Defourny Jacques, y Thorbecke, Erik (1981), "Structural Path Analysis and Multiplier Decomposition within a Social Accounting Matrix Framework", The Economic Journal, 94 (373), pp. 111-136.

Esquivel, Gerardo, y Huerta-Pineda, Alejandra (2007), "Remittances and Poverty in Mexico: A Propensity Score Matching Approach", documento de trabajo, El Colegio de México.

Fajnzylber, Pablo, y López, Humberto (2007), Close to Home: The Development Impact of Remittances in Latin America, Washington, DC, World Bank.

Fuente, Alejandro de la (2010), "Remittances and Vulnerability to Poverty in Rural Mexico", World Development, 38 (6), pp. 828-839.

Giuliano, Paola, y Ruiz-Arranz, Marta (2005), "Remittances, Financial Development and Growth", IMF Working Paper 05/234, International Monetary Fund. 
Harris, Rebecca (2002), "Estimation of a Regionalized Mexican Social Accounting Matrix: Using Entropy Techniques to Reconcile Disparate Data Sources". TMD Discussion Paper 97, International Food Policy Research Institute.

INEGIa (s.f.), "Banco de Información Económica. Año base 2003". Consultado el 10 de febrero de 2006, en: http://www.inegi.org.mx/sistemas/bie/.

INEGib (s.f.), "Encuesta Nacional de Ingresos y Gastos de los Hogares 2002", Consultado el 25 de abril de 2006, en: http://www.inegi.org.mx/est/contenidos/proyectos/ encuestas/hogares/regulares/enigh/enigh2002/default.aspx.

INEGIC (s.f.), "Anuario Estadístico de Comercio Exterior 2003”, en Instituto Nacional de Estadística y Geografia. Consultado el 23 abril de 2006, en: http://www.beta. inegi.org.mx/temas/comercio/.

INEGId (s.f.), "Censo Agrícola y Ganadero 1991". Consultado el 18 abril de 2006, en: http://www.inegi.org.mx/est/contenidos/proyectos/Agro/ca1991/Resultados Agricola/default.aspx.

Lahr, Michael, y Mesnard, Louis de (2004), "Biproportional Techniques in Input-Output” Analyss: Table Updating and Structural Analysis", Economic Systems Research, 16 (2), pp. 115-134.

Lozano, Fernando (2005), "Hogares receptores de remesas en México: límites y posibilidades para el desarrollo local y regional”, Working Paper Series \#05-02n, The Center for Migration and Development, Princeton University.

Mejía-Reyes, Pablo, y Díaz-Carreño, Miguel Ángel (2015), "Effects of the Great Recession on State Output in Mexico", Econoquantum, 12 (2), pp. 25-45.

Melo, Jaime de (1988), “sAm-Based Models: An Introduction", Journal of Policy Modeling, 10 (3), pp. 321-325.

Miller, Ronald, y Blair, Peter (2009), Input-Output Analysis. Foundations and Extensions, 2a. edición, Cambridge University Press.

Núñez, Gaspar (2014), "Macromatriz de contabilidad social de México para el año 2003”, Econoquantum, 11 (2), pp. 75-99.

Oliva, Cristian (2012), "Actualización de matrices de insumo producto de México usando el método RAS y el método de entropía cruzada", tesis de Licenciatura en Matemáticas, Universidad Autónoma de Yucatán.

Passel, Jeffrey, y Cohn, D’Vera (2009), Mexican Immigrants: How Many Come? How Many Leave?, Washington, DC, Pew Hispanic Center.

Programa de las Naciones Unidas para el Desarrollo (2007), Informe sobre desarrollo humano México 2006-2007, Programa de las Naciones Unidas para el Desarrollo. [en línea] Consultado el 11 de marzo de 2016, en: http://www.cinu.org.mx/ prensa/especiales/2007/IDH/IDH\%202006-2007.pdf 
Pyatt, Graham, y Round, Jeffery (eds.) (1985), Social Accounting Matrices: A Basis for Planning, Washington, DC, World Bank.

Robinson, Sherman (1989), "Multisectoral Models", en H. Chenery y T. N. Srinivasa, Handbook of Development Economics, Amsterdam/New York, Elsevier Science Publishing, pp. 885-947.

Robinson, Sherman; Cattaneo, Andrea, y El-Said, Moataz (1998), "Estimating a Social Accounting Matrix Using Cross Entropy Methods”, TMD Discussion Paper 33, International Food Policy Research Institute.

- (2001), "Updating and Estimating a Social Accounting Matrix Using Cross Entropy Methods", Economic Systems Research, 13 (1), pp. 47-64.

Robinson, Sherman, y El-Said, Moataz (2000), "GAMs Code for Estimating a Social Accounting Matrix (SAM) Using Cross Entropy (CE) Methods", TMD Discussion Paper 64, International Food Policy Research Institute.

Ruiz, Isabel, y Vargas-Silva, Carlos (2012), "Exploring the Causes of the Slowdown in Remittances to Mexico", Empirical Economics, 42 (3), pp. 745-766.

Sadoulet, Elizabeth, y Janvry, Alan de (1995), "Input-Output Tables, Social Accounting Matrices and Multipliers", en E. Sadoulet y A. Janvry, Quantitative Development Policy Analysis, s.1., Johns Hopkins University Press, pp. 273-301.

SAGARPA (s.f.), "Servicio de Información Agroalimentaria y Pesquera de la Secretaría de Agricultura, Ganadería, Desarrollo Rural, Pesca y Alimentación”. Consultado el 7 de marzo de 2006, en: http://infosiap.siap.gob.mx:8080/agricola_siap_ gobmx/AvanceNacionalSinPrograma.do.

Scandizzo, Pasquale, y Ferrarese, Cataldo (2015), "Social Accounting Matrix: A New Estimation Methodology", Journal of Policy Modeling, 37 (1), pp. 14-34.

Stone, Richard (1962), "Multiple Classifications in Social Accounting", Bulletin of the International Statistical Institute, 39 (3), pp. 215-233.

Taylor, Edward (1992), "Remittances and Inequality Reconsidered: Direct, Indirect, and Intertemporal Effects", Journal of Policy Modeling, 42 (2), pp. 187-208.

Taylor, Edward; Arango, Joaquin; Hugo, Graeme; Kouaouci, Ali; Massey, Douglas, y Pellegrino, Adela (1996), "International Migration and National Development", Population Index, 62 (2), pp. 181-212.

Wodon, Quentin; Ángel-Urdinola, Diego; González-Konig, Gabriel; Ojeda, Diana, y Siaens, Corina (2004), "Migration and Poverty in Mexico's Southern States", documento de discusión 16, World Bank.

World Bank (2011), Migration and Remittances Factbook 2011, Washington, DC, World Bank. 